\title{
Effect of Crystallographic Orientation on the Corrosion of Magnesium: Comparison of Film Forming and Bare Crystal Facets using Electrochemical Impedance and Raman Spectroscopy
}

\author{
Leslie G. Bland ${ }^{\mathrm{a}}$, K. Gusieva ${ }^{\mathrm{a}}$ and J.R. Scully
}

\begin{abstract}
The corrosion rate of $\mathrm{Mg}$ indicates a strong crystallographic dependence in chloride-containing, alkaline environments that correlates inversely with oxide film thickness. In contrast, a different crystallographic orientation dependency is observed initially during open circuit corrosion in non-chloride containing, near neutral $\mathrm{pH}$ buffered, chelating environments such as Tris(hydroxymethyl)aminomethane (TRIS) and Ethylenediaminetetraacetic (EDTA) which minimize air-formed $\mathrm{MgO}$ oxides. The origins of the differences in the rates of the coupled corrosion processes as a function of crystallographic orientation were investigated utilizing electrochemical impedance spectroscopy (EIS) and Raman vibrational spectroscopy. High frequency constant phase elements (CPEs) were exploited to determine oxide thicknesses as a function of crystal orientation. In unbuffered $\mathrm{NaCl}$, open circuit corrosion was faster on basal planes while lower corrosion rates were observed on low index, prismatic and pyramidal planes. This variation in rate with crystallographic orientation in $0.6 \mathrm{M} \mathrm{NaCl}$ was interpreted to depend on the $\mathrm{MgO}$ and $\mathrm{Mg}(\mathrm{OH})_{2}$ film thicknesses as a function of orientation. In particular, crystal planes with a lower $\mathrm{MgO} / \mathrm{Mg}(\mathrm{OH})_{2}$ thickness corroded at higher rates as assessed in-situ by EIS and suggested by Raman spectroscopy. The crystallographic orientation dependence of corrosion seen initially upon exposure in the buffered neutral $\mathrm{pH}$ environments corresponded with crystal facet surface energy for bare $\mathrm{Mg}$ but this trend disappeared with exposure time and $\mathrm{Mg}(\mathrm{OH})_{2}$ films were then detected.
\end{abstract}

Bland 


\section{INTRODUCTION}

\subsection{Corrosion Dependence on Crystallographic Orientation for Various Metal Systems}

For many metals and alloys, the corrosion rate has been found to exhibit strong dependence on crystallographic orientation [1-5]. Assessing anisotropic corrosion properties by using single crystal samples limits the number of facets tested $[3,4,6,7]$. While such studies give an indication of the corrosion properties of specific orientations, limitation to a few crystal planes can confound understanding of the corrosion properties of the system as a whole $[3,4,6,7]$. This paucity of grain orientations at closely spaced h, k, 1 Miller-Bravais indices values falls short because corrosion properties can vary significantly over only a few degrees difference in crystallographic orientation [1]. Consideration of a large number of grains on polycrystalline samples on a grain by grain basis over small differences in $\mathrm{h}, \mathrm{k}, \mathrm{l}$ values provides the opportunity to uncover the true orientation dependence of dissolution and corrosion rate as a function of surface plane orientation.

Moreover, significant differences in findings as well as interpretation of crystal orientation effects on corrosion often occur [1-13]. For body-centered cubic (bcc) stainless steel in 0.6 M $\mathrm{NaCl}$, the highest percentage of pitting events was observed on planes oriented $\sim 25^{\circ}$ away from $\{001\}$ [8] while in contrast the $\{100\}$ orientation was reported to have the highest corrosion rate in $\mathrm{H}_{2} \mathrm{SO}_{4}$ [2] and $\mathrm{NO}_{3}{ }^{-}$[9]. For face-centered cubic (fcc) $\mathrm{Al}$ in $\mathrm{NaOH}$, orientations near $\{111\}$ indicated the most corrosion [10-12]. The effects of crystal structure on atomic bonding between nearest neighbors, coordination, the number of dangling bonds and resultant surface energy, film thickness, film/substrate epitaxy $[1,2,6,13]$ as well as the reaction thermodynamics and kinetics at the metal-oxide-solution interface during both passive and active corrosion should all be considered to better understand the influence of crystallographic orientation on corrosion $[3,7]$. However, a careful comparison is required on the same alloy under both film covered and bare, actively dissolving conditions because orientation effects may differ in each case.

\subsection{Crystallographic Orientation Dependence on Corrosion for Mg and Mg Alloys}

A systematic sampling of orientations in Mg alloys is lacking or has been complicated due to the substantial crystallographic texture of $\mathrm{Mg}$ alloy sheet or plate often formed upon mechanical 
processing [14-17]. For these reasons, as well as the historical inability to accurately assess corrosion and dissolution rates in $\mathrm{Mg}$ system by electrochemical methods [18-20], conflicting results have been reported regarding the orientation dependence of $\mathrm{Mg}$ corrosion [21, 22]. Corrosion was observed on planes that were oriented with a normal near the $<0001>$ direction with respect to the sample surface in $\mathrm{NaCl}$ environments containing dichromate ions [23]. One study examined $\mathrm{Mg}$ in $0.1 \mathrm{~N} \mathrm{HCl}$ and studied grains after EBSD and AFM where the (0001) planes were argued to be most corrosion resistant [22]. The basis for this claim is unclear. Many grains with high orientations exhibited striations after corrosion that were argued to be made up of $\{20 \overline{2} 1\},\{0001\},\{11 \overline{2} 0\}$ and $\{01 \overline{1} 0\}$ planes. Some of these facets are likely slowly dissolved planes seen after fast dissolving planes grow themselves out of existence as shown elsewhere [1]. When tested in $\mathrm{NaCl}$, the rolling plane (heavily textured to favor the basal plane) of wrought AZ31 exhibited greater $\mathrm{H}_{2}$ evolution than cross-sections suggesting an effect of texture on corrosion rate but the difference was later attributed to the prevalence of particles such as $\mathrm{Al}_{8} \mathrm{Mn}_{5}$ and not crystal orientation effects [21, 24]. The $\mathrm{Mg}$ (0001) surface exhibited pitting

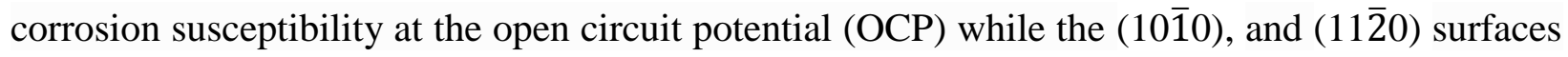
were passive at open circuit and pitting only initiated at potentials slightly anodic to their open circuit potentials in a similar environment [25].

Validation of the corrosion rate of various crystallographic orientations in $\mathrm{Mg}$ based materials has also involved alloys [26, 27]. Mg-Al alloys (such as AZ31) corroded at a lower rate on the closely packed basal plane [26], although this was also complicated by the presence of secondary phases. In another study, SKP, SVET, EIS and E-log(j) were focused on two $\mathrm{Mg}$ grains in $\mathrm{NaCl}$ and saturated $\mathrm{Mg}(\mathrm{OH})_{2}$ solution [21]. One had an orientation between (0001) and (1010) and the other was close to $(11 \overline{2} 0)$ on a grain facet which also contained twins. The grain near (0001) had the greatest corrosion rate by EIS and E- $\log (\mathrm{j})$ and the oxide film was thinner, which is similarly shown by the work in this study. The corrosion dependency might have been governed by film thickness as the (0001) film was thinner. This was not reported but evident from the work. The authors were instead concerned that films "concealed" the effects of orientation, not recognizing that it might be a controlling factor [21]. No other orientations were attempted. Therefore, there is limited comprehensive comparison between the corrosion rate and overall effects of 
dissolution on the resultant morphology on many individual grains as a function of crystallographic orientation not clouded by these factors.

The work herein comprises of a full analysis of the EIS frequency response on polycrystalline materials as well as an in depth analysis on the corrosion morphology via SEM and Electron Backscatter Diffraction (EBSD). Rate data is correlated with Raman spectroscopy in both attempts to produce film free and film covered cases. In work to date on the crystallographic orientation on $\mathrm{Mg}$, while there has been some work on polycrystalline pure Mg samples [21, 22], the work has only evaluated a few orientations and has not shown a wide breath in the evaluation techniques. In particular EBSD correlated with surface topography measurements, such as profilometry techniques now enables understanding of the dissolution behavior of a large number of crystal planes [1] as has been performed here. In this study, these prior difficulties have been overcome by EBSD analysis of many grains. Profilometry and electrochemical impedance spectroscopy (EIS) were both conducted on individual, isolated grains to reveal the orientation dependence of corrosion under open circuit conditions.

\subsection{Effect of Surface Energy on Crystallographic Dissolution}

Existing literature on $\mathrm{Mg}$ suggests that surface energy varies with crystal orientation. The surface energy for $\mathrm{Mg}\{0001\},\{10 \overline{1} 0\}$ and $\{10 \overline{1} 2\}$ surfaces are $0.9,1.2$ and $1.4 \mathrm{~J} / \mathrm{m}^{2}$, respectively, as calculated with empirical electron theory $[6,28]$. This implies that exposed faces close to the $\{0001\}$ plane should have a lower thermodynamic driving force and might corrode slower than those planes which are oriented slightly different than the $\{0001\}$ plane from a surface energy minimization perspective [23]. Previous work on bare fcc Fe-Pd shows that the highest dissolution occurred at planes oriented approximately $45^{\circ}$ from the $\{100\}$ orientation which correlated to the highest determined surface energy [1]. However, $\mathrm{Mg}$ is a system which corrodes in $\left[\mathrm{Cl}^{-}\right]$solutions far from equilibrium [1].

\subsection{Nature and Crystallographic Aspects of the Native Oxide Film on Mg}

For $\mathrm{Mg}$, the oxide film is affected by factors such as solution $\mathrm{pH}$, where a more protective film is typically formed in alkaline solutions [29-32]. Several techniques have been used to analyze the 
nature of this film. The surface film formed on $\mathrm{Mg}$ is duplex in nature, consisting of a thin, nanocrystalline $\mathrm{MgO}$ inner layer and a $\mathrm{Mg}(\mathrm{OH})_{2}$ platelet layer [33-35]. X-ray photoelectron spectroscopy (XPS) [36-38] and focused ion beam (FIB) [29, 35, 39] studies on the surface of $\mathrm{Mg}$ have shown that the surface film consists of both $\mathrm{MgO}$ and $\mathrm{Mg}(\mathrm{OH})_{2}$ [40]. The initial, crystalline $\mathrm{MgO}$ layer is formed during exposure to air. Hydration of the bulk inner $\mathrm{MgO}$ layer occurs and the layer thickens to form the outer $\mathrm{Mg}(\mathrm{OH})_{2}$ corrosion product $[29,35]$. The thickness of the oxide layer on Mg has been calculated through XPS and FIB cross-section [29, 35, 39]. While this thickness is extremely dependent on exposure time and environment, the outer, $\mathrm{Mg}(\mathrm{OH})_{2}$ layer is typically on the order of $\sim 500 \mathrm{~nm}$ in thickness and flake-like while the inner $\mathrm{MgO}$ layer is only on the order of $50-90 \mathrm{~nm}$ thick [29, 35, 39]. MgO films on the basal $\{0001\}$ surface are thinner than those on either $\{01 \overline{1} 0\}$ and $\{11 \overline{2} 0\}$ in dilute sodium sulphate solutions [41]. This relationship has been similarly reported for polycrystalline hexagonal close packed (hcp) Ti using EBSD measurements [42]. While the $\{0001\}$ and $\{01 \overline{1} 0\}$ planes consist of equiaxed crystals of $\mathrm{MgO}$, the $\{11 \overline{2} 0\}$ surface forms $\mathrm{MgO}$ with oriented flakes perpendicular to the metal/oxide interface $[29,35]$.

\subsection{Opportunity to Ascertain Crystallographic Dependence of Simultaneous Corrosion and Oxide Formation with Impedance Spectroscopy}

The use of electrochemical impedance spectroscopy (EIS) gives a reliable and repeatable estimation of the instantaneous corrosion rate on $\mathrm{Mg}$ and its alloys [18-20]. The components of the equivalent circuit have been shown to correspond to the Mg sample surface and described in terms of their physical meaning [43]. Therefore, oxide film thickness may be determined under in-situ conditions. The goal of this research was to utilize EIS to understand the effects of crystallography on oxide thickness and corrosion rate for oxide 'free' and oxide covered crystal surfaces.

The EIS determined oxide thickness has been achieved for other material systems, such as $\mathrm{Ni}$ Cr-Mo [44], Al [45, 46] and the hcp Zr [5] but further analysis in the Mg system is needed. The circuit diagram for accurate EIS determination in $\mathrm{Mg}$ has been recently suggested in other work respective to the oxide growth (Figure 2) [43]. The use of two capacitive circuit elements is necessary in order to model the full frequency response of the $\mathrm{Mg}$ to the electrolyte [18, 43]. The 
high frequency capacitor, $\mathrm{C}_{1}$ represents the passive oxide and possibly $\mathrm{Mg}(\mathrm{OH}) 2$ films while the low frequency capacitor, $\mathrm{C}_{2}$ represents the double-layer capacitance or pseudo-capacitance. These two capacitances can be simultaneously determined in the case where the capacitances differ in magnitude [43]. Good correlation has been shown between the percent area of corroded surface and the capacitive elements [43, 47], showing that the thickness of this oxide with time can be determined by these capacitive values.

\subsection{Objective}

The objective of this study is to understand origins of the crystallographic dependence of the corrosion and dissolution rate in a polycrystalline $\mathrm{Mg}$ sample under film and film-free conditions. The work herein is the first of its kind to perform EIS on a large number of single grains in a polycrystalline material system (as compared to single crystals) in order to assess both oxide thickness and to determine the open circuit corrosion rate as a systematic function of orientation.

\section{EXPERIMENTAL PROCEDURES}

\subsection{Materials}

Extruded commercially pure $\mathrm{Mg}$ rod was provided by Alfa Aesar. The sample was re-melted and re-solidified to randomize the texture or minimize the as-received extruded texture. All compositions are reported in wt. \%, provided by QUANT (Quality Analysis and Testing Corporation) via Inductively Coupled Plasma optical Emission Spectroscopy (ICP-OES) analysis (Table 1).

\subsection{Metallurgical Sample Characterization}

\subsubsection{Sample Heat Treatment for Large Grain Growth}

All polycrystalline samples have been heat treated to alleviate deformation twins formed during previous processing. Commercially pure $\mathrm{Mg}$ samples were heat treated at $575^{\circ} \mathrm{C}$ for $5 \mathrm{~h}$ to achieve a grain size of approximately $1.5 \mathrm{~mm}$ in diameter. This enabled grains to be easily located by SEM, EIS and optical microscopy before and after corrosion. 


\subsubsection{Electron Backscatter Diffraction}

Optical and electron microscopy as well as scanning electron microscopy (SEM) were performed using a Hirox optical and FEI Quanta 650 microscope, respectfully. Samples were polished through colloidal silica, ion flat milled and etched with a Picric acid etch ( 3 g picric acid, $30 \mathrm{~mL}$ acetic acid, $100 \mathrm{~mL}$ ethanol and $15 \mathrm{~mL}$ distilled water) immediately before being placed in the SEM. Etching removed the $\mathrm{MgO}$ oxide which may have formed, even after ion polishing, to enable improved EBSD imaging. Samples were rapidly polished $(\ll<\mu \mathrm{m})$ to maintain some of the etched microstructure for grain identification after EBSD but to remove any carbon contamination from the SEM before corrosion analysis. EBSD was performed at low magnification to image a large number of grains at once and analyzed using Aztec ${ }^{\mathrm{TM}}$ [48]. Approximately 200 grains were analyzed over multiple EBSD micrographs.

\subsubsection{Corrosion Morphology and Oxide Thickness in Various Electrolyte Environments}

Secondary electron SEM micrographs were taken of each sample before and after immersion in unbuffered $0.6 \mathrm{M} \mathrm{NaCl}, 0.1 \mathrm{M}$ Tris(hydroxymethyl)aminomethane (TRIS) and $0.1 \mathrm{M}$ Ethylenediaminetetraacetic acid (EDTA) for $12 \mathrm{~h}$ at OCP. The starting $\mathrm{pH}$ for each of these environments was 5.1, 7 and 8, respectfully. TRIS and EDTA are both chelating, buffering agents, which chemically dissolve oxide films and, therefore, enable $\mathrm{Mg}$ corrosion studies without a thick $\mathrm{MgO}$ or $\mathrm{Mg}(\mathrm{OH})_{2}$ oxide layer [49]. All samples were cleaned after corrosion testing with $\mathrm{CrO}_{3}$ to remove any corrosion products and examine the corrosion morphology [50]. 3D images were also obtained using a Hirox optical microscope to determine the depth of corrosion. The area-fraction of the sample surface which was corroded in the form of dark areas, if observed, was determined using the software package, Image ${ }^{\mathrm{TM}}$ [51]. The corroded areafraction of the sample surface was determined using the software package Mountains ${ }^{\circledR}$ [52].

\subsubsection{Surface and Corrosion Film Characterization}

Raman spectroscopy was performed utilizing a Renishaw InVia Raman Microscope after exposure to $0.6 \mathrm{M} \mathrm{NaCl}, 0.1 \mathrm{M}$ TRIS and $0.1 \mathrm{M}$ EDTA after immersion in these various 
environments for $24 \mathrm{~h}$ at OCP. Samples were analyzed utilizing a $514 \mathrm{~nm}$ laser at $50 \%$ power under at 50x objective lens with $3000 \mathrm{l} / \mathrm{mm}$ grating. Raman analysis was performed on approximately three spots on the sample surface and a typical Raman spectrum is reported.

\subsubsection{Texture and Orientation Determination of Each Grain}

The Euler angle $\Phi$ from the Bunge convention was used to report the $\{$ hkil\} pole normal to the orientation of a surface exposed crystal facet in a grain [53]. The Euler angles of each plane normal, with respect to the $\left\{\begin{array}{lllll}0 & 0 & 0 & 1\end{array}\right\}$ plane, were reported, as exported from the Aztec [48] software, and the $\{$ hkil $\}$ were determined from Equation 1 [54].

$\left[\begin{array}{l}\mathrm{h} \\ \mathrm{k} \\ \mathrm{i} \\ \mathrm{l}\end{array}\right]=\left[\begin{array}{ccc}\frac{\sqrt{3}}{2} & -\frac{1}{2} & 0 \\ 0 & 1 & 0 \\ -\frac{\sqrt{3}}{2} & -\frac{1}{2} & 0 \\ 0 & 0 & \frac{\mathrm{c}}{\mathrm{a}}\end{array}\right]\left[\begin{array}{c}\sin \phi_{2} \sin \phi \\ \cos \phi_{2} \sin \phi \\ \cos \phi\end{array}\right]$

Equation 1

Where $\mathrm{h}, \mathrm{k}, \mathrm{i}$ and $\mathrm{l}$ are the Miller-Bravais indices and c/a is approximately $1.624 \mathrm{for} \mathrm{Mg}$, where $\mathrm{c}$ $=5.21 \AA$ and $\mathrm{a}=3.21 \AA$.

To describe the Miller-Bravais index of each plane on an exposed grain facet, \{hkil\}, the variables, described in Figure 1, were used to describe a given $\{$ hkil $\}$ on an inverse pole figure (IPF). The $\{$ hkil $\}$ was defined in terms of the interplanar angles, $\beta_{\mathrm{i}}$, the angle measured from a primary low index hexagonal plane normal to the $\{$ hkil $\}$ of interest and the $\alpha_{i}$, the angle between

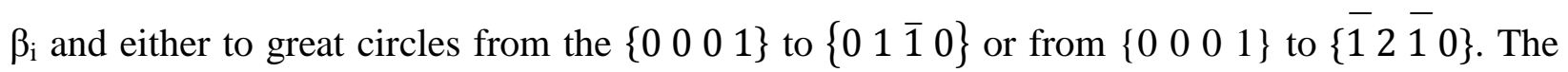
interplanar angles between any two planes $\left\{h_{1} k_{1} i_{1} l_{1}\right\}$ and $\left\{h_{2} k_{2} i_{2} l_{2}\right\}$ in the hexagonal system were determined from Equation 2 [55].

$$
\cos \emptyset=\frac{\mathrm{h}_{1} \mathrm{~h}_{2}+\mathrm{k}_{1} \mathrm{k}_{2}+\frac{1}{2}\left(\mathrm{~h}_{1} \mathrm{k}_{2}+\mathrm{h}_{2} \mathrm{k}_{1}\right)+\frac{3 \mathrm{a}^{2}}{4 \mathrm{c}^{2}} \mathrm{l}_{1} \mathrm{l}_{2}}{\sqrt{\left(\mathrm{h}_{1}^{2}+\mathrm{k}_{1}^{2}+\mathrm{h}_{1} \mathrm{k}_{1}+\frac{3 \mathrm{a}^{2}}{4 \mathrm{c}^{2}} \mathrm{l}_{1}^{2}\right)\left(\mathrm{h}_{2}^{2}+\mathrm{k}_{2}^{2}+\mathrm{h}_{2} \mathrm{k}_{2}+\frac{3 \mathrm{a}^{2}}{4 \mathrm{c}^{2}} \mathrm{l}_{2}^{2}\right)}}
$$

Bland 


\subsection{Corrosion Behavior Determination by EIS}

The corrosion behavior of single grain facets of commercially pure $\mathrm{Mg}$ was monitored with EIS over a $24 \mathrm{~h}$ immersion period in $0.6 \mathrm{M} \mathrm{NaCl}, 0.1 \mathrm{M}$ TRIS and 0.1 M EDTA at OCP. The isolation of individual grain facets was accomplished using electroplaters tape with a $1.23 \mathrm{~mm}^{2}$ area hole to expose each grain. EIS data were acquired from $100 \mathrm{kHz}$ to $0.001 \mathrm{~Hz}$ with 6 points per decade and an AC amplitude of $\pm 20 \mathrm{mV}$. EIS scans were analyzed and fit using the software program ZView [56] to fit an equivalent circuit, seen in Figure 2, and were fit to a low frequency limit of at least $0.01 \mathrm{~Hz}$ for $0.1 \mathrm{M}$ TRIS and $0.1 \mathrm{M}$ EDTA and to $0.001 \mathrm{~Hz}$ for $0.6 \mathrm{M} \mathrm{NaCl}$.

Figure 2(a) consists of a set of series and parallel resistors and capacitors [i.e., $R_{1} /\left(R_{2} / / C_{2}\right)$ ], (where "/" indicates series and "//" indicates parallel) and a series resistor inductor combination (i.e., $\mathrm{R}_{3} / \mathrm{L}$ ). Figure 2 (b) has excluded this last series resistor inductor combination as the final inductive loop does not appear in the TRIS and EDTA environments. In this circuit, $\mathrm{R}_{\mathrm{s}}$ in the circuit represents the solution resistance and is specific to the exposure environment. $R_{1}, R_{2}$ and $\mathrm{R}_{3}$ represent the various resistances due to oxides and hydroxides as well as anodic and cathodic reactions on the $\mathrm{Mg}$ surface or oxide/film interface which are affected by the local environment $[18,19,43]$. The capacitors (or in some cases CPE's), $\mathrm{C}_{1}$ represents the capacitance associated with the oxide/hydroxide layers. $\mathrm{C}_{1}$ is similar to the parallel combination of $\mathrm{C}_{\mathrm{ox}}$ and $\mathrm{C}_{\mathrm{AF}}$ for oxide/hydroxide and the air oxide used elsewhere [43]. $\mathrm{C}_{2}$ may be a double layer capacitance, adsorption pseudo-capacitance and may differ based on environment. $R_{1}+R_{2}$ are related to the oxide resistance and interface charge transfer resistance, respectively. (termed the $\mathrm{R}_{\mathrm{CT}}$ in this and other work [19-20, 43, 57]. Last, the inductor $\mathrm{L}_{1}$ represents a reaction rate that changes with the reaction mediating coverage of intermediates.

The inclusion of the full inductive frequency response of $\mathrm{Mg}$ enables for a more accurate determination of the anodic charge produced for $\mathrm{Mg}$ alloys by the inclusion of the full polarization resistance, $R_{p}$, established at low frequencies $[18,19]$. The determination of $R_{P}$ was calculated using the following equation as reported elsewhere $[18,19,43]$ for Figure 2(a) and 2(b) respectively. 
Where $R_{1}, R_{2}$ and $R_{3}$ represent the resistors within the circuit model and have been defined above. The anodic charge produced for each grain was determined through integration of $1 / R_{p}(t)$ with respect to time using the Stern-Geary equation [58] as detailed in Equation 5.

$\mathrm{Q}_{\mathrm{a}}^{\mathrm{EIS}}=\int \mathrm{j}_{\operatorname{corr}(\theta)} \mathrm{dt}=\int \frac{\beta_{\mathrm{a}} \beta_{\mathrm{c}}}{2.303 \mathrm{R}_{\mathrm{P}}(\mathrm{t})\left(\beta_{\mathrm{a}}+\beta_{\mathrm{c}}\right)} \mathrm{dt}$

Equation 5

It has been shown previously, that the Mg interface as interrogated by $\mathrm{AC}$ methods in chloridecontaining environment can be considered reasonably stationary through the direct integration of the Kramers-Kronig (K-K) transformations of the real and imaginary components $[59,60]$. There is good correlation and low residual noise ( $<<1 \%$ of calculated) as low as $0.001 \mathrm{~Hz}$ for $0.6 \mathrm{M}$ $\mathrm{NaCl}$ (Figure 3(a)). Recall that the inductive loop, which is typically observed on $\mathrm{Mg}$ in the chloride-containing environments at low frequencies is observed in unbuffered $0.6 \mathrm{M} \mathrm{NaCl}$ [19]. However, in the TRIS and EDTA environments, good correlation could only be achieved up to $0.01 \mathrm{~Hz}$ (Figure 3(b-c)). There is no valid inductive loop in the scattered data seen at low frequencies. This agrees with previous work which has found that this solution lacked a welldefined inductive loop as it is typically seen in the $\left[\mathrm{Cl}^{-}\right]$environments [19].

The corrosion penetration depth was calculated from Faraday's law:

$\mathrm{x}=\frac{\mathrm{Q}(\mathrm{E} \cdot \mathrm{W} \cdot)}{\mathrm{F} \rho}$

Equation 6

Where E.W. is the equivalent weight of commercially pure $\mathrm{Mg}$, taken as $12.16 \mathrm{~g} / \mathrm{eq}, \mathrm{F}$ is Faraday's constant $(96,485 \mathrm{C} / \mathrm{eq})$, and $\rho$ is the density of $\mathrm{Mg}$. This corrosion depth is important for single grain EIS analysis, particularly for highly reactive $\mathrm{Mg}$ samples. If the material corrodes deeper than the depth of a grain (relative to $x=0 \mu \mathrm{m}$ at the sample surface) then the crystallographic dependence determined through single grain EIS is lost ${ }^{1}$. Therefore, an absolute upper bound in corrosion was taken as the grain size/2. However, it is recognized that corrosion

\footnotetext{
${ }^{1}$ It is recognized that the fast dissolving planes may largely dissappear at lower depths than the grain diameter to reveal slow dissolving facets as seen in ref 1 . However, EBSD is a bulk technique sampling electrons from depths over which dissolution occurred.
} 
beyond the first 100 atom layers may result in a corroded surface different from the crystallographic orientation of the face of the grain first exposed [1].

\subsection{Film Thickness Determination by EIS}

The film thickness on individual grains was determined by EIS over a $24 \mathrm{~h}$ immersion period in $0.6 \mathrm{M} \mathrm{NaCl}, 0.1 \mathrm{M}$ TRIS and 0.1 M EDTA using the software program ZView [56] to fit experimental data to the equivalent circuit Figure 2(a) for $0.6 \mathrm{M} \mathrm{NaCl}$ or Figure 2(b) for 0.1 M TRIS and EDTA ${ }^{2}$ solutions due to the variation in physical presence or absence of films. The equivalent circuits were comprised of constant phase elements (CPEs). A CPE impedance, $\mathrm{Z}_{\mathrm{CPE}}$, can be expressed in terms of the model parameters $\alpha$ (a time-constant) and $\mathrm{Y}_{\mathrm{O}}$ (CPE parameter) as shown in Equation 7 [61] were the CPE parameter was used for $\mathrm{C}_{1}$ for determining the inner oxide thickness.

$\mathrm{Z}_{\mathrm{CPE}}=\frac{1}{(\mathrm{j} \omega)^{\alpha} \mathrm{Y}_{\mathrm{o}}}$

Equation 7

Where $\mathrm{j}$ is an imaginary number and $\omega$ is the AC frequency response. The oxide film can be modeled as a capacitor [43]. For an ideal capacitor, $\alpha=1$, where $Y_{0}=C$, however, $\alpha$ varied in Figure $2(a, b)$ with time. In the case of an ideal capacitor, the effective dielectric capacitance, $\mathrm{C}_{\mathrm{eff}}^{\mathrm{id}}$, of the film can be expressed by Equation 8 .

$C_{\text {eff }}^{\text {id }}=\frac{\varepsilon \varepsilon_{0} A}{\mathrm{l}_{\mathrm{ox}}}$

Equation 8

Where $\varepsilon$ is the dielectric constant for $\mathrm{MgO}$ taken to be $9.8, \varepsilon_{\mathrm{o}}$ is the permittivity of vacuum $\left(8.84 \times 10^{-14} \mathrm{~F} / \mathrm{cm}\right)[62], \mathrm{A}$ is the sample exposure area and $\mathrm{l}_{\mathrm{ox}}$ is the oxide thickness. In the case of a non-ideal capacitor (such as in Figure 2(a-b)), the effective capacitance, $\mathrm{C}_{\mathrm{eff}}^{\text {non-id }}$ can be obtained from a constant phase element [63].

$\mathrm{C}_{\text {eff }}^{\text {non-id }}=\mathrm{Y}_{\mathrm{o}}\left(2 \pi \omega^{\prime \prime}\right)^{\alpha-1}$

Equation 9

Where $\omega$ " is the frequency where $\mathrm{Z}_{\mathrm{CPE}}$ reaches a maximum [63]. From determination of $\mathrm{C}_{\text {eff }}$ non-id as necessary, Equation 8 can be used to determine the oxide thickness from $\mathrm{C}_{1}$. For this analysis,

\footnotetext{
${ }^{2}$ Data below the K-K transform limit determining data that was not valid was excluded in this analysis.

Bland
} 
$\mathrm{Y}_{\mathrm{o}}$ and $\alpha$ for $\mathrm{C}_{1}$ and $\mathrm{C}_{2}$ respectively, were both determined via fitting of the equivalent circuits (Figure 2).

\section{RESULTS}

\subsection{Materials Characterization}

The commercially pure $\mathrm{Mg}$ grains were equiaxed and approximately $1.5 \mathrm{~mm}$ in diameter with a heterogeneous distribution of grain sizes determined by the line intercept method. The texture of the samples were determined from EBSD, reported in an inverse pole figure (IPF), to be approximately random which yielded numerous grains with various crystallographic orientations to ascertain the crystallographic orientation dependence of corrosion. Few deformation twins were seen.

\subsection{Electrochemical Impedance Behavior in Film and Non-Film Forming Environments}

Corrosion dependence on the crystallographic orientations was influenced by the exposure environment. Specifically, film-forming versus non-film forming environments affected the resultant intrinsic corrosion rate and morphology. Examining the EIS frequency response in 0.6 $\mathrm{M} \mathrm{NaCl}$ versus $0.1 \mathrm{M}$ TRIS and 0.1 M EDTA (Figure 4, Table 2), it was observed that, after 24 $\mathrm{h}$, TRIS and EDTA had the highest corrosion rates. This may be indicative of the absence of a thick, partially protective surface film, consisting of $\mathrm{MgO} / \mathrm{Mg}(\mathrm{OH})_{2}$ as has been reported in literature $[35,39,64,65]$. Higher corrosion rates may also be indicative of the lack of changes in the local surface environment in these buffered solutions, specifically usual elevation of $\mathrm{pH}$ towards the $\mathrm{Mg}^{+2} / \mathrm{Mg}(\mathrm{OH})_{2}$ equilibrium [66]. The $\mathrm{pH}$ for the chloride containing environments before exposure was typically around 5.3 before becoming more alkaline with the generation of $\mathrm{OH}^{-}, \sim 10$, immediately after corrosion of $\mathrm{Mg}$ in the unbuffered solution. At $\mathrm{pH} \sim 10, \mathrm{MgO}$ and $\mathrm{Mg}(\mathrm{OH})_{2}$ are thermodynamically stable [66, 67]. However, the bulk $\mathrm{pH}$ of the buffer solutions remained near 7 and 8 which would not thermodynamically support the formation of $\mathrm{MgO}$ or $\mathrm{Mg}(\mathrm{OH})_{2}$. Mg exposed to $0.1 \mathrm{M}$ TRIS and $0.1 \mathrm{M}$ EDTA showed max $1 / \mathrm{R}_{\mathrm{p}}$ or $\mathrm{j}_{\text {corr }}$ at intermediate $\beta$-angles suggesting a crystallographic orientation dependence that will be discussed below (Figure 5(a-f)). However, samples exposed to $0.6 \mathrm{M} \mathrm{NaCl}$ (Figure 6) showed various corrosion morphologies as a function of the initial crystallographic orientation after the samples were 
cleaned with $\mathrm{CrO}_{3}$. The low index $\left\{\begin{array}{lllll}0 & 1 & \overline{1} & 0\end{array}\right\}$ indicated a wide "filiform-like" corrosion morphology while other, higher index grains, showed terraces instead of this filiform type morphology [1].

The molecular identity of the oxide films, formed in the $0.6 \mathrm{M} \mathrm{NaCl}, 0.1 \mathrm{M}$ TRIS and $0.1 \mathrm{M}$ EDTA exposure environments, were confirmed through Raman spectroscopy (

Figure 7). Fitting of the Raman shift to the characteristic $\operatorname{Mg}(\mathrm{OH})_{2}$ peaks indicated a strong presence of the $\mathrm{Mg}(\mathrm{OH})_{2}$ film in the chloride containing $0.6 \mathrm{M} \mathrm{NaCl}$ solution. These peaks had a lower intensity in the EDTA and TRIS solutions which suggests that only a small amount of $\mathrm{Mg}(\mathrm{OH})_{2}$ was present which was likely a remnant of the air formed film or due to metastable film formation. It is noted that analysis of the Raman signal should be treated with caution. In particular, the assessment here is not to give a quantitative evaluation of oxide thickness with Raman Spectroscopy. Instead, this technique simply gives an assessment of the presence of this oxide. $\mathrm{MgO}$ (or the $\mathrm{MgO}$ stretch) was not detected through Raman Spectroscopy, even after thermal oxidation of the material suggesting significant hydroxylation of oxides. However, an assessment of the relative peak intensity ratios can give some understanding into the amount of oxide present on the sample surface as a function of exposure environment following previous work on $\mathrm{Pb}$ oxides using a similar method [68]. The relative peak intensity ratios of the oxides for two characteristic Raman peaks are reported in Table 3 where the peak intensity was determined from the normalized peak intensities in Figure 7. This analysis indicates more $\mathrm{Mg}(\mathrm{OH})_{2}$ in the $\mathrm{NaCl}$ environment than either TRIS or EDTA.

\subsection{Crystallographic Dependent Corrosion in Polycrystalline Mg}

Polycrystalline samples were exposed to $0.6 \mathrm{M} \mathrm{NaCl}$ after EBSD characterization. The orientation of each grain was determined, as shown in Figure 8(a) and 9(a). The colors on the EBSD map correspond to those shown in Figure 1(b). After a $12 \mathrm{~h}$ immersion at open circuit in $0.6 \mathrm{M} \mathrm{NaCl}$, some grains preferentially corroded and developed characteristic dark areas [20, 43, 49] while other grains remained intact. In Figure 8(b), grain 18 was substantially corroded by the filiform morphology [69-72]. This grain had an orientation approximately $20^{\circ}$ from the $\left\{\begin{array}{llll}0 & 0 & 0 & 1\end{array}\right\}$ basal plane. However, grains 21 and 19, near $\left\{\begin{array}{llll}\overline{1} & 2 & 1 & 0\end{array}\right\}$ orientations, had not corroded. Figure 9 displays a grain with a strong basal orientation (red grain 1). The near basal plane (labeled as 1) 
corroded preferentially to those of a non-basal orientation. The corrosion depth (Equation 6) in $0.6 \mathrm{M} \mathrm{NaCl}$ is approximately $57 \mu \mathrm{m}$ on the basal plane after 24 hours while this depth is $225 \mu \mathrm{m}$ and $450 \mu \mathrm{m}$ for $0.1 \mathrm{M}$ TRIS and 0.1 M EDTA, respectively (Figure 10(a-d)). The relationship between the corrosion depth is roughly linear with time for each specified [h $\mathrm{k} \mathrm{i}$ l] indicating an approximately constant corrosion rate. Also, the trend shows a lower corrosion propagation depth at each time with increasing $\beta_{\{0001\}}$ from the basal plane that is maintained over all exposure times. Therefore, the trend with initial surface crystallographic orientation is preserved through the full exposure time for each environment.

Figure 11(a) shows the percent "dark" surface area [65, 73] for different orientations after immersion in $0.6 \mathrm{M} \mathrm{NaCl}$ for $24 \mathrm{~h}$ at OCP. This percent has been calculated based on the dark area relative to the surface area of the grain. As the material dissolves, the sample surface becomes dark [73] and this dark region typically contains enriched transition elements [74, 75] and for AZ31B possibly by Al chemical deposition [47]. The exchange current density for the hydrogen evolution reaction (HER), the dominant cathodic reaction on $\mathrm{Mg}$, increases with time due to this enhanced cathodic activity $[64,76,77]$. The dissolution behavior can also be plotted as the volume of material dissolved (Figure 11(b)). The dissolution, expressed as volume, is highest on $\left\{\begin{array}{llll}0 & 0 & 0 & 1\end{array}\right\}$ oriented grain facets. More specifically, grains oriented within $\sim 30^{\circ}$ of the

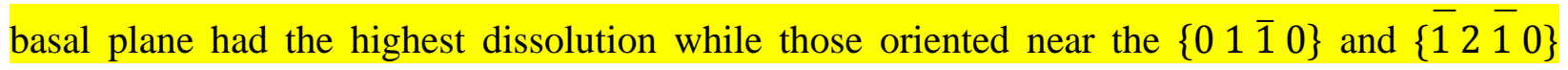
planes had the least dissolution.

\subsection{Crystallographic Dependence on the Instantaneous Corrosion Rate on Isolated Mg Grains}

For commercially pure $\mathrm{Mg}$, the EIS spectra at OCP in $0.6 \mathrm{M} \mathrm{NaCl}$ had two capacitive loops and an inductive loop [37, 78-85] as determined from the fits in Figure 12. Using the equivalent circuit shown in Figure 2(a), a reasonable fit was achieved with $\alpha=0.95$ for the CPE. This $\alpha<1$ is typical for the case of surface heterogeneity [86] and would be particularly true for the highly reactive $\mathrm{Mg}$ system. Concerning $\mathrm{R}_{\mathrm{p}}$ as a function of $\beta_{\{0001)}$ angle, in Figure $12, \mathrm{R}_{\mathrm{p}}$ increases with increasing $\beta_{\{0001)}$ meaning that the $\mathrm{j}_{\text {corr }}$ decreased with increasing $\beta_{\{0001)}$ (away from the basal crystal surface) which is quite consistent with the corrosion morphology observed in Figure 8-9. It was shown that the basal plane had the highest anodic charge produced the low index planes 
had the lowest anodic charge produced in the unbuffered $\mathrm{NaCl}$ solution. This is consistent with $\%$ dark area and volume lost (Figure 11) in the $\mathrm{NaCl}$ solution.

EIS spectra for non-chloride containing TRIS and EDTA solution were also collected for specific grain orientations at various $\beta_{\{0001)}$ angles (Figure 13-14). These solutions lack a welldefined inductive loop that is typically seen in the $\left[\mathrm{Cl}^{-}\right]$environments and therefore $1 / \mathrm{R}_{\mathrm{p}}$ was fit to the equivalent circuit Figure 2(b). There is a slight variation in these environments with this trend with time. In TRIS, at $0 \mathrm{~h}$ there is a small peak in the anodic charge density produced over the range $\beta_{\{0001\}}=20^{\circ}-60^{\circ}$ (potentially due to a surface energy effect to be discussed below) (Figure 13). However, this trend disappears after $3 \mathrm{~h}$, with the $1 / \mathrm{R}_{\mathrm{p}}$ increasing with increasing $\beta_{\{0001\}}$. This same trend was also determined in the non-chloride containing EDTA solution (Figure 14).

For each of these environments, the corrosion current density was integrated over the full $24 \mathrm{~h}$ immersion for each of these specified crystallographic orientations (Figure 15). It is shown that, in the $0.6 \mathrm{M} \mathrm{NaCl}$ environment the anodic charge density from open circuit corrosion (Equation 5) and corrosion depth (as determined via Equation 6) decrease with increasing $\beta_{\{0001)}$ angle. However, in the TRIS and EDTA environments, there is also a small peak in anodic charge after open circuit corrosion and depth around $\beta_{\{0001)}=60^{\circ}$. This correlates to the plane with the highest surface energy $[6,28]$.

\subsection{Effect of Oxide Thickness on the Crystallographic Orientation Dependent Corrosion of $M g$}

The model-determined oxide thickness (determined through Equation 8) was highly dependent on the capacitive response in the $\mathrm{Mg}$ system [43]. $\mathrm{C}_{1}$ typically had a value of $\sim 10^{-6} \mathrm{~F} / \mathrm{cm}^{2}$ in $\mathrm{NaCl}$ while $\mathrm{C}_{2}$ had a value of approximately $\sim 10^{-5} \mathrm{~F} / \mathrm{cm}^{2}$ or larger depending on active dark area [43]. However, in TRIS and EDTA $C_{1}$ was $\sim 10^{-5} \mathrm{~F} / \mathrm{cm}^{2}$ while $\mathrm{C}_{2}$ ranged from $10^{-4}$ to $10^{-3} \mathrm{~F} / \mathrm{cm}^{2}$. From a sensitivity analysis using circuit model Figure 2(a), replacing CPE with a capacitor, $\mathrm{C}_{1}$ can be distinguished from $\mathrm{C}_{2}$ when $\mathrm{C}_{2} \neq \mathrm{C}_{1}$. However, when $\mathrm{C}_{1}$ was similar to $\mathrm{C}_{2}$ one $1^{\text {st }}$ quadrant depressed semi-circle appears as the time constants for $\mathrm{R}_{1} \mathrm{C}_{1}$ and $\mathrm{R}_{2} \mathrm{C}_{2}$ are too similar to produce two distinct depressed semicircles (Figure 16(a-b)). EIS fitting in $0.6 \mathrm{M} \mathrm{NaCl}$ (Figure 12), $\mathrm{C}_{1}$ 
and $\mathrm{C}_{2}$ might be similar depending on dark area while, in Figure 13-14 (i.e. in TRIS and EDTA) the values differ. The oxide thickness was determined in the circuit model of Figure 2(a), initially assuming a CPE. $\mathrm{Y}_{\mathrm{o}}$ was close to an ideal capacitor, with $\alpha \sim 0.95$ for most fits (Equation 7-9). In summary, $\mathrm{l}_{\mathrm{ox}}$, for the compact $\mathrm{MgO}$ layer, as determined through Equation 8, was determined from $\mathrm{C}_{1}$ (using a CPE).

The EIS determined oxide thickness is plotted in Figure 17 for $0.6 \mathrm{M} \mathrm{NaCl}$. The change in this thickness was plotted as a function of the $\beta_{\{0001\}}$ value or the distance from the basal plane Figure 17(a). It was observed that the planes furthest from the basal plane had the thickest determined oxide $(\sim 40 \mathrm{~nm})$ while those planes close to the basal plane had a thinner oxide thickness $(\sim 5 \mathrm{~nm})$ which is consistent with the results reported elsewhere [29, 35, 37-39]. The total amount of charge was inversely proportional to this thickness (Figure 15).

The oxide thickness as a function of $\beta$ angle was also determined for the non-chloride containing TRIS and EDTA environments (Figure 17(b-c)). The oxide thickness was determined using the equivalent circuit in Figure 2(b) and EIS data which is $\mathrm{K}-\mathrm{K}$ valid to $0.01 \mathrm{~Hz}$ (Figure 3). The oxide thickness was extremely small, if physically present and if realistically appraised by the approach here on the basal planes $(\sim 0 \mathrm{~nm})$ and slightly higher on the pyramidal and prismatic planes $(\sim 1 \mathrm{~nm}){ }^{3}$ This EIS calculated oxide thickness was clearly much smaller than in the $0.6 \mathrm{M}$ $\mathrm{NaCl}$ environment. This also agreed with the Raman which strongly suggests that either the high corrosion rate of $\mathrm{Mg}$ eventually saturates the buffer capacity of TRIS and EDTA or a $\mathrm{Mg}(\mathrm{OH})_{2}$ remnant of the air oxide exists (Figure 7). Moreover, the variation in the $j_{\text {corr }}$ with the calculated oxide thickness was much smaller for all crystallographic orientations in the EDTA and TRIS environments.

\footnotetext{
${ }^{3}$ One interpretation is that this is the remnant of the original air form oxide incompletely dissolved in TRIS or EDTA. The oxide thickness determined by EIS may be inaccurate if there are patches of oxide present.It is also possible that $\mathrm{C}_{1}$ and $\mathrm{C}_{2}$ represent the double layer and a pseudo-capacitance in EDTA and TRIS and the oxide thickness dimension is not valid.

Bland
} 


\section{DISCUSSION}

\subsection{Variation in the Oxide Dissolution and Precipitation with Exposure Environment}

Figure 18(a) shows a schematic of the oxide growth on $\mathrm{Mg}$ in $0.6 \mathrm{M} \mathrm{NaCl}$ [39], consisting of a duplex $\mathrm{MgO} / \mathrm{Mg}(\mathrm{OH})_{2}$ oxide. The thick, plate-like $\mathrm{Mg}(\mathrm{OH})_{2}$ layer (approximately $500 \mathrm{~nm}$ ) and is formed after exposure to $\mathrm{H}_{2} \mathrm{O}[29,35]$ due to the hydration of the inner $\mathrm{MgO}$ layer and formation of $\mathrm{Mg}(\mathrm{OH})_{2}$ onto the sample surface [35, 39, 71]. The initial $\mathrm{MgO}$ layer nucleates on the Mg surface and is determined to be on the order or $50 \mathrm{~nm}[29,35]$.

The phenomenon is different in the buffered 0.1 M TRIS and 0.1 M EDTA solutions (Figure 18(b)). Once the sample is exposed to this solution, the air-formed $\mathrm{MgO}$ oxide is likely dissolved for the most part by the TRIS/EDTA solution. The remaining air-formed $\mathrm{MgO}$ is converted to $\mathrm{Mg}(\mathrm{OH})_{2}$ at the sample surface and buffer capacity is exceeded, therefore a small $\mathrm{Mg}(\mathrm{OH})_{2}$ signal was detected by Raman Spectroscopy (

Figure 7). In the chloride environments, the typical $\mathrm{pH}$ after exposure is on the order of $\sim 10$ due to the alkalization of the bulk $\mathrm{NaCl}$ solution to $\mathrm{pH}$ values in the stable region for $\mathrm{Mg}(\mathrm{OH})_{2}$ according to the Mg Pourbaix diagram [87]. However, both TRIS and EDTA are buffer solutions with stable $\mathrm{pH}$ values of 7 and 8 , respectfully, which would lead to less oxide formation according to the $\mathrm{Mg}$ Pourbaix diagram even after $\mathrm{Mg}^{2+}$ production [87].

There was a notable difference in the thickness of this oxide as a function of both crystallographic orientation and test solution with the thinnest oxide on the basal plane and the thickest oxide on the low index orientations for each environment (Figure 17(a-c)). The thickness of this oxide is inversely proportional to the corrosion rate (as denoted $\mathrm{j}_{\text {corr }}$ ). From the EIS determined $j_{\text {corr }}$, the oxide thickness was on the order of $5 \mathrm{~nm}$ to $50 \mathrm{~nm}$ in $0.6 \mathrm{M} \mathrm{NaCl}$ and $<<1$ $\mathrm{nm}$ to $1 \mathrm{~nm}$ in $0.1 \mathrm{M}$ TRIS and 0.1 M EDTA. MgO forms a fcc crystal structure with the Fm3m structure that in equilibrium has an epitaxial relationship with hcp $\mathrm{Mg}$ [88]. The oxide thickness on a different hcp material, $\mathrm{Zr}$, was also determined through EIS [5, 89]. The basal plane had a slower oxidation rate compared to the prismatic planes $[5,89]$. This variation in oxide growth kinetics was argued to be due to the variation in the oxygen diffusion kinetics through the high 
packed basal plane and the lower packed prismatic plane $[5,89]$ which can lead to lower rates of passivation.

\subsection{Corrosion Rates on Oxide Covered Mg Surfaces}

In the chloride, film-forming environment, there was a large variation in the corrosion rates, morphology and the oxide film thickness with crystallographic orientation (Figure 6). The presence or absence of this oxide has been shown to alter the corrosion kinetics on $\mathrm{Mg}$ [90]. The $\mathrm{j}_{\text {corr }}$ increased with decreasing oxide thickness in $0.6 \mathrm{M} \mathrm{NaCl}$ (Figure 17(a) and Figure 19(a)). The trend reported here agrees with the literature [25] where the (0001) surface exhibited more corrosion susceptibility at the OCP while the (10 $\overline{1} 0)$, and $(11 \overline{2} 0)$ surfaces are typically passive at open circuit and pit at potentials anodic to their OCPs [25]. In other studies, corrosion occurred more readily on planes near the basal orientation [23]. This inverse proportionality can be explained if oxidation "flux rate" of $\mathrm{Mg}^{2+}$ is dependent on oxide film thickness. Suppose that oxidation was controlled by a Wagner type law. Corrosion rate due to flow of $\mathrm{Mg}^{2+}$ and $\mathrm{O}^{2-}$ or electrons and holes are both inversely proportional to oxide thickness [91]. More specifically, a more rapid passivation rate on the prismatic and pyramidal orientations may in turn lead to overall lower aqueous corrosion rates on these surfaces (Figure 17). Thicker hydroxides may also limit water penetration and cation transport. The thinnest oxide as well as the highest anodic charge produced over the $24 \mathrm{~h}$ period was observed on the basal plane (Figure 17). This suggests substantial direct cation ejection must occur as the anodic charge is much greater than that required for the film thicknesses noted. Consequentially, the total anodic charge density produced (Figure 15) would not necessarily mean better passivation because the anodic charge density produced does not contribute to oxide formation. This agrees with the work shown here where the film covered basal plane had the highest anodic charge density (Figure 15) over $24 \mathrm{~h}$ in $0.6 \mathrm{M} \mathrm{NaCl}$. However, the oxide on this film did not lead to better passivation in this aggressive environment. 


\subsection{The Effect of Surface Energy on Corrosion Thermodyanmics}

The effect of surface energy on corrosion is a factor in the corrosion of bare or almost bare $\mathrm{Mg}$, such as in TRIS or EDTA. Referring to Figure 17(b-c) and Figure 19(b-c), it can be seen that $j_{\text {corr }}$ roughly follows surface energy trends (for short immersion times) estimated for $\mathrm{Mg}$ from embedded atom method and empirical electron theory [28, 92]. These calculation techniques show that, in vacuum, the surface energy $(\gamma)$ varies from 0.9 to $1.4 \mathrm{~J} / \mathrm{m}^{2}$ (Figure 19(c)) and even as high as $1.65 \mathrm{~J} / \mathrm{m}^{2}[28,92]$. Of course this is in vacuum and the actual value of $\gamma$ in TRIS and EDTA is unknown. The standard free energy of the following reaction applies to the case of $\mathrm{Mg}$ corroding in an acid where, in such a half-cell reaction, the number of nearest neighbors is not considered:

$$
\begin{gathered}
\mathrm{Mg} \rightarrow \mathrm{Mg}^{2+}+2 \mathrm{e}^{-}\left(E^{0, M g}\right) \\
2 \mathrm{H}^{+}+2 \mathrm{e}^{-} \rightarrow \mathrm{H}_{2}\left(E^{0, S H E}\right)
\end{gathered}
$$

Equation 12

Equation 13

Or the overall reaction is:

$\mathrm{Mg}+2 \mathrm{H}^{+} \rightarrow \mathrm{Mg}^{2+}+\mathrm{H}_{2}$

Equation 14

This reaction will occur spontaneously in water. Consider the free energy of the reaction in Equation 14 under standard conditions at room temperature, where $\mathrm{Mg}$ corrodes in acidified water at unity activity of the dissolved species.

$\Delta_{\mathrm{r}} \mathrm{G}^{0}=-\mathrm{nF} \Delta \mathrm{E}^{0}=-\mathrm{nF}\left(\mathrm{E}^{0, \mathrm{SHE}}-\mathrm{E}^{0, \mathrm{Mg}}\right)$

Equation 15

In the case where $\mathrm{E}^{0, \mathrm{SHE}}=0 \mathrm{~V}$ and $\mathrm{E}^{0, \mathrm{Mg}}=-2.36 \mathrm{~V}$. Therefore, $\Delta_{\mathrm{r}} \mathrm{G}^{0}=-456 \mathrm{kJmol}^{-1}$ for $\mathrm{n}=$ 2 and $\mathrm{F}=96485 \mathrm{C} / \mathrm{eq}$. The free energy of the overall reaction is quite negative. However, this energy is lowered by irrational planes which contain kinks, ledges and terraces containing many atoms with fewer bonds than the $\{0001\}$ plane. This energy may be estimated from the surface energy difference per atom assuming a close packed surface converted to energy per mole:

$$
\mathrm{k} \Delta \gamma=\left(\frac{1.4 \mathrm{~J}}{m^{2}}-\frac{0.9 \mathrm{~J}}{m^{2}}\right)\left(\frac{m^{2}}{1 \times 10^{19} \text { atoms }}\right)\left(\frac{6.023 \times 10^{23} \text { atoms }}{m o l}\right)=30.1 \mathrm{kJmol}^{-1} \quad \text { Equation } 16
$$

for the case of high energy surface sites with $1.4 \mathrm{~J} / \mathrm{m}^{2}$ as determined from $\beta_{\{0001\}}=60^{\circ}$ along $\alpha=0^{\circ}$ compared to $0.9 \mathrm{~J} / \mathrm{m}^{2}$ for the close packed $\{0001\}$ plane $[28,92]$, Here $\gamma$ is the surface energy term as shown in Figure 19(c) and $\mathrm{k}$ is a correction factor. The free energy change for the overall reaction given by Equation 14 is more favorable by $30.1 \mathrm{~kJ} / \mathrm{mol}$.

Bland 
This is equivalent to a lowered standard half-cell potential, $\mathrm{E}_{\{\text {hkil }\}}^{0, \mathrm{Mg}}$, now written to describe a specific $\{$ hkil $\}$ plane:

$\mathrm{E}_{\{\mathrm{hkil}\}}^{0, \mathrm{Mg}}=\frac{\sum \nu \mu_{\mathrm{ox}}-\sum v \mu_{\mathrm{red}}-\sum v \mathrm{k} \Delta \gamma_{\{\mathrm{hkil}\}}}{\mathrm{nF}}$

Equation 17

When $n=2$ and $v$ is the stoichiometric coefficient. Under these conditions, the standard half-cell potential, $\mathrm{E}_{\{\mathrm{hkil}\}}^{0, \mathrm{Mg}}$, would be lowered from $-2.36 \mathrm{~V}$ to $-2.52 \mathrm{~V}$ for $\beta_{\{0001\}}=60^{\circ}$ along $\alpha=0^{\circ}$ compared to a $\{0001\}$ plane and the additional thermodynamic driving force is $160 \mathrm{mV}$.

However, this indicates that the reaction occurs more readily from a thermodynamic view. This driving force is not great ( $7 \%$ change) for $\mathrm{Mg}$ because the oxidation reaction already occurs at OCP (such as $-1.74 \mathrm{~V}_{\mathrm{SCE}}$ ) far from equilibrium. Thus, the effect of surface energy is rationalized to produce some effect on bare electrodes but it is easily overcome by other factors, such as the role of the oxide which regulates $\mathrm{j}_{\text {corr }}$ as discussed above. It is recognized that kinetics effects such as lowering the activation barrier for $\mathrm{Mg}$ oxidation are not accounted for.

\subsection{Corrosion Rates on Mg Bare surfaces}

The effect of crystallographic orientation on OCP corrosion rate was observed in exposure environments where the $\mathrm{MgO}$ film is dissolved and little of the $\mathrm{Mg}(\mathrm{OH})_{2}$ film was precipitated as envisioned in Figure 18. The variation in $\mathrm{j}_{\text {corr }}$ with crystallographic orientation was different than that in the unbuffered, chloride environments (Figure 15, 17, and 19) with a slight increase in $\mathrm{j}_{\text {corr }}$ at $\beta_{\{0001\}}=35-60^{\circ}$. This trend correlates with the vacuum surface energy (Figure 19(b-c)). TRIS and EDTA removed most of the oxide film. This would lead to the correlation between $\mathrm{j}_{\text {corr }}$ and surface energy (Figure 19 (b-c) with a slight increase in $j_{\text {corr }}$ at intermediate $\beta_{\{0001\}}$ from 35 to $60^{\circ}$ (Figure 17). It can be speculated that by removing the effects of the oxide film, $\mathrm{j}_{\text {corr }}$ might correlate better with surface energy. However, $\mathrm{j}_{\text {corr }}$ exhibited a correlation with high surface energy only at short exposure times (Figure 19(b)). This correlation during the initial stages of immersion is particularly seen in Figure 17(b-c) after 0 hours in EDTA and TRIS where there is little oxide formed. However, after longer immersion times, the surface energy trends with 
orientation are no longer dominant, potentially because the rapid $\mathrm{j}_{\text {corr }}$ of $\mathrm{Mg}$ resulted in local saturation of the buffer solution which triggered local oxide formation.

\section{CONCLUSIONS}

1. A method was reported to acquire EIS derived $\mathrm{j}_{\text {corr }}$ data from isolated individual grain facets with specific crystallographic orientations identified by the EBSD method. Anodic charge and corrosion rate were both accurately calculated from $\mathrm{R}_{\mathrm{p}}$, determinations during open circuit corrosion of $\mathrm{Mg}$ for a large number of specified crystallographic orientations. Corrosion properties of $\mathrm{Mg}$ were highly dependent on both the crystal orientations of the exposes grain facets, the corrosive environment, and time.

2. Open circuit corrosion, as a function of crystallographic orientation, exhibited a trend towards a faster corrosion rate and greater anodic charge at orientations near the $\{0001\}$ plane relative to others for commercially pure magnesium exposed in unbuffered, sodium chloride and also after long exposures in buffered chelating environments.

3. In contrast, open circuit corrosion, as a function of crystallographic orientation, exhibited a trend towards a faster corrosion rate and greater anodic charge at orientations associated with crystal surfaces with high surface energies. These high index planes were found at intermediate Beta angles within the stereographic triangle in buffered, chelating environments. However, this trend was only observed for short term exposures.

4. Film formation is highly dependent on the exposure environment and time. A thick precipitated $\mathrm{Mg}(\mathrm{OH})_{2}$ film with an inner $\mathrm{MgO}$ layer was readily formed in alkaline, chloride environments in unbuffered solutions in short time periods. Meanwhile, this film did not form as readily in the near neutral $\mathrm{pH}$, non-chloride TRIS and EDTA solutions, leading to a crystallographic orientation dependence that correlated with the surface energy of high index planes at short exposure times.

5. Oxide thickness was strongly dependent on crystallographic orientation in the chloride containing environment, 0.6 M NaCl. The thickest oxide was observed on the (10 $\overline{1} 0)$, and $(11 \overline{2} 0)$ planes while the thinnest oxide was found on the (0001) plane after several hours which was preserved at longer times. The corrosion rate was inversely proportional to 
oxide thickness and the subsequent crystal orientation dependency of corrosion correlated with orientation effects on oxide thickness.

6. In the non-chloride TRIS and EDTA environments, a slight increase in the corrosion charge was seen at $\beta_{\{0001\}}=60^{\circ}$ and a correlation between high corrosion rate and high surface energies associated with high index planes was seen. The crystallographic orientation dependence on the corrosion rate was related to the effect of surface energy on the $1 / 2$ cell potential for $\mathrm{Mg}$ oxidation to $\mathrm{Mg}^{2+}$, even though open circuit corrosion of $\mathrm{Mg}$ occurs at open circuit potentials far from this equilibrium potential. However, the surface energy correlation was observed to be overtaken with time by the strong oxide film orientation dependency consistent with $\mathrm{Mg}(\mathrm{OH})_{2}$ film detection by Raman Spectroscopy.

\section{Acknowledgements}

This student (LB) was funded by the Office of Naval Research Grant N000141210967 with Dr. David A. Shifler as scientific officer. The NSF under DMR-130999 and ONR under Grant SP0028970-PROJ0007990 supported JRS. The U.S. Government is authorized to reproduce and distribute reprints for Governmental purposes notwithstanding any copyright notation thereon. The views and conclusions contained herein are those of the authors and should not be interpreted as necessarily representing the Office of Naval Research and the Technical Corrosion Collaboration. 


\section{References:}

[1] D. Horton, A. Zhu, J. Scully, M. Neurock, Crystallographic controlled dissolution and surface faceting in disordered facecentered cubic FePd, MRS Communications, 4 (2014) 113-119.

[2] K. Fushimi, K. Miyamoto, H. Konno, Anisotropic corrosion of iron in pH 1 sulphuric acid, Electrochimica Acta, 55 (2010) $7322-7327$.

[3] B.W. Davis, P.J. Moran, P.M. Natishan, Metastable pitting behavior of aluminum single crystals, Corrosion Science, 42 (2000) 2187-2192.

[4] M. Yasuda, F. Weinberg, D. Tromans, Pitting Corrosion of Al and Al-Cu Single-Crystals, Journal of The Electrochemical Society, 137 (1990) 3708-3715.

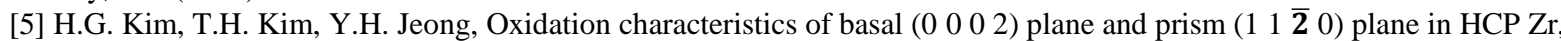
Journal of Nuclear Materials, 306 (2002) 44-53.

[6] R.S. Lillard, G.F. Wang, M.I. Baskes, The role of metallic bonding in the crystallographic pitting of magnesium, Journal of The Electrochemical Society, 153 (2006) B358-B364.

[7] G.M. Treacy, C.B. Breslin, Electrochemical studies on single-crystal aluminium surfaces, Electrochimica Acta, 43 (1998) $1715-1720$.

[8] J.A.S. A. Shahryari, and S. Orrianovic, The influence of crystallographic orientation distribution on 316LVM stainless steel pitting behavior, Corrosion Science, 51 (2009).

[9] A.S. M.M. Lohrengel, and C. Rosenkranz, Grain-dependent anodic dissolution of iron, Electochimica Acta, 52 (2007).

[10] N.L. B. Holme, A. Bakken, O. Lunder, J.E. Lein, L. Vines, T. Hauge, a.K.N. O. Bauger, Preferential grain etching of AlMgSi(Zn) model alloys, Journal of The Electrochemical Society, 157 (2010) C424.

[11] G.E.T. E.V. Koroleva, P. Skeldon, and B. Noble, Crystallographic dissolution of high purity aluminium, proceedings of the royal society of london A, 463 (2007) 1729.

[12] E.V.K. M. Gentile, P. Skeldon, G.E. Thompson, P. Bailey, and T.C., Q. Noakes, Influence of grain orientation on zinc enrichment and surface morphology of an Al-Zn alloy, Surface and Interface Analysis, 42 (2010).

[13] B. Holme, N. Ljones, A. Bakken, O. Lunder, J.E. Lein, L. Vines, T. Hauge, O. Bauger, K. Nisancioglu, Preferential Grain Etching of AlMgSi(Zn) Model Alloys, Journal of The Electrochemical Society, 157 (2010) C424-C427.

[14] U. Konig, B. Davepon, Microstructure of polycrystalline Ti and its microelectrochemical properties by means of electronbackscattering diffraction (EBSD), Electrochimica Acta, 47 (2001) 149-160.

[15] E.V. Koroleva, G.E. Thompson, P. Skeldon, B. Noble, Crystallographic dissolution of high purity aluminium, P R Soc A, 463 (2007) 1729-1748.

[16] A. Schreiber, J.W. Schultze, M.M. Lohrengel, F. Karman, E. Kalman, Grain dependent electrochemical investigations on pure iron in acetate buffer pH 6.0, Electrochimica Acta, 51 (2006) 2625-2630.

[17] A. Shahryari, J.A. Szpunar, S. Orrianovic, The influence of crystallographic orientation distribution on 316LVM stainless steel pitting behavior, Corrosion Science, 51 (2009) 677-682.

[18] A.D. King, N. Birbilis, J.R. Scully, Accurate Electrochemical Measurement of Magnesium Corrosion Rates; a Combined Impedance, Mass-Loss and Hydrogen Collection Study, Electrochimica Acta, 121 (2014) 394-406.

[19] L.G. Bland, A.D. King, N. Birbilis, J.R. Scully, Assessing the Corrosion of Commercially Pure Magnesium and Commercial AZ31B by Electrochemical Impedance, Mass-loss, Hydrogen Collection and ICP-OES Solution Analysis, Corrosion, 71 (2015) $128-145$.

[20] L.G. Bland, J.M. Fitz-Gerald, J.R. Scully, Metallurgical and Electrochemical Characterization of the Corrosion of AZ31BH24 Tungsten Inert Gas Weld: Isolated Weld Zones, Corrosion, 72 (2016) 1116-1132.

[21] G.-L. Song, Z. Xu, Crystal orientation and electrochemical corrosion of polycrystalline Mg, Corrosion Science, 63 (2012) $100-112$.

[22] M. Liu, D. Qiu, M.-C. Zhao, G. Song, A. Atrens, The effect of crystallographic orientation on the active corrosion of pure magnesium, Scripta Materialia, 58 (2008) 421-424.

[23] P. Schmutz, V. Guillaumin, R.S. Lillard, J.A. Lillard, G.S. Frankel, Influence of Dichromate Ions on Corrosion Processes on Pure Magnesium, Journal of The Electrochemical Society, 150 (2003) B99-B110.

[24] G.-L. Song, R. Mishra, Z. Xu, Crystallographic orientation and electrochemical activity of AZ31 Mg alloy, Electrochemistry Communications, 12 (2010) 1009-1012.

[25] M.A.H. C.R. McCall, R.S. Lillard, Crystallographic pitting in magnesium single crystals, Corrosion Engineering Science and Technology, 40 (2005) 337-343.

[26] G.L. Song, Z. Xu, Effect of microstructure evolution on corrosion of different crystal surfaces of AZ31 Mg alloy in a chloride containing solution, Corrosion Science, 54 (2012) 97-105.

[27] M.C. Zhao, M. Liu, G.-L. Song, A. Atrens, influence of the beta-phase morphology on the corrosion of the Mg alloy AZ91, Corrosion Science, 50 (2008) 1939-1953.

[28] B.Q. Fu, W. Liu, Z.L. Li, Calculation of the surface energy of hcp-metals with the empirical electron theory, Applied Surface Science, 255 (2009) 9348-9357.

[29] M. Taheri, J.R. Kish, Nature of Surface Film Formed on Mg Exposed to $1 \mathrm{M} \mathrm{NaOH}$, Journal of The Electrochemical Society, 160 (2013) C36-C41.

[30] D.A. Vermilyea, C.F. Kirk, Studies of Inhibition of Magnesium Corrosion, Journal of The Electrochemical Society, 116 (1969) 1487-1492. 
[31] E. Gulbrandsen, J. Taftø, A. Olsen, The passive behaviour of Mg in alkaline fluoride solutions. Electrochemical and electron microscopical investigations, Corrosion Science, 34 (1993) 1423-1440.

[32] W.A. Badawy, N.H. Hilal, M. El-Rabiee, H. Nady, Electrochemical behavior of Mg and some Mg alloys in aqueous solutions of different pH, Electrochimica Acta, 55 (2010) 1880-1887.

[33] J.H. Nordlien, S. Ono, N. Masuko, Morphology and Structure of Oxide Films Formed on Magnesium by Exposure to Air and Water, Journal of The Electrochemical Society, 142 (1995) 3320-3322.

[34] Y. Zhu, G. Wu, Y.H. Zhang, Q. Zhao, Growth and characterization of $\mathrm{Mg}(\mathrm{OH})_{2}$ film on magnesium alloy AZ31, Applied Surface Science, 257 (2011) 6129-6137.

[35] M. Taheri, R.C. Phillips, J.R. Kish, G.A. Botton, Analysis of the surface film formed on Mg by exposure to water using a FIB cross-section and STEM-EDS, Corrosion Science, 59 (2012) 222-228.

[36] H.B. Yao, Y. Li, A.T.S. Wee, An XPS investigation of the oxidation/corrosion of melt-spun Mg, Applied Surface Science, 158 (2000) 112-119.

[37] S. Feliu, C. Maffiotte, A. Samaniego, J.C. Galvan, V. Barranco, Effect of the chemistry and structure of the native oxide surface film on the corrosion properties of commercial AZ31 and AZ61 alloys, Applied Surface Science, 257 (2011) 8558-8568. [38] S. Feliu, J.C. Galván, A. Pardo, M.C. Merino, R. Arrabal, Native Air-Formed Oxide Film and its Effect on Magnesium Alloys Corrosion, Corrosion, 3 (2010).

[39] R.C. Phillips, J.R. Kish, Nature of Surface Film on Matrix Phase of Mg Alloy AZ80 Formed in Water, Corrosion, 69 (2013) 813-820.

[40] K. Nisancioglu, Morphology and Structure of Oxide Films Form on Magnesium by Exposure to Air and Water, Journal of The Electrochemical Society, 142 (1995).

[41] B. McNally, Crystallographic Orientation Dependence of Film Formation on Corrosion Magnesium, CorrosionSan Antonio, TX, 2014.

[42] U. König, B. Davepon, Microstructure of polycrystalline Ti and its microelectrochemical properties by means of electronbackscattering diffraction (EBSD), Electrochimica Acta, 47 (2001) 149-160.

[43] M. Curioni, F. Scenini, T. Monetta, F. Bellucci, Correlation between electrochemical impedance measurements and corrosion rate of magnesium investigated by real-time hydrogen measurement and optical imaging, Electrochimica Acta, 166 (2015) 372-384.

[44] P. Jakupi, D. Zagidulin, J.J. Noël, D.W. Shoesmith, The impedance properties of the oxide film on the Ni-Cr-Mo Alloy-22 in neutral concentrated sodium chloride solution, Electrochimica Acta, 56 (2011) 6251-6259.

[45] J. Bessone, C. Mayer, K. Jüttner, W.J. Lorenz, AC-impedance measurements on aluminium barrier type oxide films, Electrochimica Acta, 28 (1983) 171-175.

[46] J.B. Bessone, D.R. Salinas, C.E. Mayer, M. Ebert, W.J. Lorenz, An EIS study of aluminium barrier-type oxide films formed in different media, Electrochimica Acta, 37 (1992) 2283-2290.

[47] M. Danaie, R.M. Asmussen, P. Jakupi, D.W. Shoesmith, G.A. Botton, The cathodic behaviour of Al-Mn precipitates during atmospheric and saline aqueous corrosion of a sand-cast AM50 alloy, Corrosion Science, 83 (2014) 299-309.

[48] AZtecEnergy: EDS Software, Oxford Instruments, (2015).

[49] L.G. Bland, B.C.R. Troconis, R.J.S. Jr., J.M. Fitz-Gerald, J.R. Scully, Metallurgical and Electrochemical Characterization of the Corrosion of Mg-Al-Zn Alloy AZ31B-H24 Tungsten Inert Gas Weld: Galvanic Corrosion Between Weld Zones Corrosion, 72 (DOI: 10.5006/2078) (2016) 1226-1242.

[50] ASTM-G1, Standard Practice for Preparing, Cleaning, and Evaluating Corrosion Test Specimens, ASTM International, G1 (2011).

[51] C.A. Schneider, W.S. Rasband, K.W. Eliceiri, NIH Image to ImageJ: 25 years of image analysis, Nature Methods, 9 (2012) 671-675.

[52] D. Surf, MountianMaps, 2016.

[53] H.J. Bunge, Texture analysis in materials science : mathematical methods, 1982.

[54] J.C.H. Y.N. Wang, texture analysis in hexagonal materials, Materials Chemistry and Physics, 81 (2003) 11-26.

[55] D.W. Hogan, D.J. Dyson, Angles between planes in the hexagonal and tetragonal crystal systems, Micron (1969), 2 (1970) 59-61.

[56] S. Associates, ZView.

[57] L.G. Bland, N. Birbilis, J.R. Scully, Exploring the Effects of Intermetallic Particle Size and Spacing on the Corrosion of MgAl Alloys Using Model Electrodes, Journal of The Electrochemical Society, 163 (2016) C895-C906.

[58] M. Stern, A.I. Geary, Journal of The Electrochemical Society, 104 56-63.

[59] A.H. Carl H. Hamann, Wolf Vielstich, Electrochemistry, 2nd, Completely Revised and Updated Edition, 2nd ed.2007.

[60] F. Mansfeld, Electrochemical impedance spectroscopy (EIS) as a new tool for investigating methods of corrosion protection, Electrochimica Acta, 35 (1990) 1533-1544.

[61] B. Hirschorn, M.E. Orazem, B. Tribollet, V. Vivier, I. Frateur, M. Musiani, Constant-Phase-Element Behavior Caused by Resistivity Distributions in Films II. Aplications, Journal of The Electrochemical Society, 157 (2010) C458-C463.

[62] B. Hirschorn, M.E. Orazem, B. Tribollet, V. Vivier, I. Frateur, M. Musiani, Constant-Phase-Element Behavior Caused by Resistivity Distributions in Films I. Theory, Journal of The Electrochemical Society, 157 (2010) C452-C457.

[63] C.H. Hsu, F. Manfeld, Technical Note: Concerning the Conversion of the Constant Phase Element Parameter $\mathrm{Y}_{0}$ into a Capacitance, Corrosion, 57 (2001). 
[64] G. Williams, H. ap Llwyd Dafydd, R. Grace, The localised corrosion of Mg alloy AZ31 in chloride containing electrolyte studied by a scanning vibrating electrode technique, Electrochimica Acta, 109 (2013) 489-501.

[65] G. Williams, N. Birbilis, H.N. McMurray, The source of hydrogen evolved from a magnesium anode, Electrochemistry Communications, 36 (2013) 1-5.

[66] M. Pourbaix, Atlas of electrochemical equilibria in aqueous solutions, National Association of Corrosion Engineers, Huston, TX, 1974.

[67] L. Rossrucker, A. Samaniego, J.-P. Grote, A.M. Mingers, C.A. Laska, N. Birbilis, G.S. Frankel, K.J.J. Mayrhofer, The pH Dependence of Magnesium Dissolution and Hydrogen Evolution during Anodic Polarization, Journal of The Electrochemical Society, 162 (2015) c333-c339.

[68] L. Black, G.C. Allen, P.C. Frost, Quanitification of Raman Spectra for the PRimary Atmospheric Corrosion Products of Lead, Applied Spectroscopy, 49 (1995) 1299-1303.

[69] A. Samaniego, I. Llorente, S. Feliu Jr, Combined effect of composition and surface condition on corrosion behaviour of magnesium alloys AZ31 and AZ61, Corrosion Science, 68 (2013) 66-71.

[70] G. Williams, R. Grace, Chloride-induced filiform corrosion of organic-coated magnesium, Electrochimica Acta, 56 (2011) 1894-1903.

[71] Z.P. Cano, M. Danaie, J.R. Kish, J.R. McDermid, G.A. Botton, G. Williams, Physical Characterization of CathodicallyActivated Corrosion Filaments on Magnesium Alloy AZ31B, Corrosion, 71 (2015) 146-159.

[72] Z.P. Cano, J.R. McDermid, J.R. Kish, Cathodic Activity of Corrosion Filaments Formed on Mg Alloy AM30, Journal of The Electrochemical Society, 162 (2015) C732-C740.

[73] G. Williams, H.N. McMurray, Localized Corrosion of Magnesium in Chloride-Containing Electrolyte Studied by a Scanning Vibrating ElectrodeTechnique, Journal of The Electrochemical Society, 155 (2008) C340-C349.

[74] N. Birbilis, T. Cain, J.S. Laird, X. Xia, J.R. Scully, A.E. Hughes, Nuclear Microprobe Analysis for Determination of Element Enrichment Following Magnesium Dissolution, Journal of The Electrochemical Society, 4 (2015) C34-C37. [75] T. Cain, S.B. Madden, N. Birbilis, J.R. Scully, Evidence of the Enrichment of Transition Metal Elements on Corroding Magnesium Surfaces Using Rutherford Backscattering Spectrometry, Journal of The Electrochemical Society, 162 (2015) C228C237.

[76] G.S. Frankel, A. Samaniego, N. Birbilis, Evolution of hydrogen at dissolving magnesium surfaces, Corrosion Science, 70 (2013) 104-111.

[77] N. Birbilis, A.D. King, S. Thomas, G.S. Frankel, J.R. Scully, Evidence for enhanced catalytic activity of magnesium arising from anodic dissolution, Electrochimica Acta, 132 (2014) 277-283.

[78] G. Song, A. Atrens, D. St John, X. Wu, J. Nairn, The anodic dissolution of magnesium in chloride and sulphate solutions, Corrosion Science, 39 (1997) 1981-2004.

[79] G. Baril, C. Blanc, M. Keddam, N. Pebere, Local electrochemical impedance spectroscopy applied to the corrosion behavior of an AZ91 magnesium alloy, Journal of The Electrochemical Society, 150 (2003) B488-B493.

[80] G. Baril, C. Blanc, N. Pebere, AC impedance spectroscopy in characterizing time-dependent corrosion of AZ91 and AM50 magnesium alloys - Characterization with respect to their microstructures, Journal of The Electrochemical Society, 148 (2001) B489-B496.

[81] G. Baril, G. Galicia, C. Deslouis, N. Pebere, B. Tribollet, V. Vivier, An impedance investigation of the mechanism of pure magnesium corrosion in sodium sulfate solutions, Journal of The Electrochemical Society, 154 (2007) C108-C113.

[82] G. Baril, N. Pebere, The corrosion of pure magnesium in aerated and deaerated sodium sulphate solutions, Corrosion Science, 43 (2001) 471-484.

[83] I. Nakatsugawa, R. Martin, E.J. Knystautas, Improving Corrosion Resistance of AZ91D Magnesium Alloy by Nitrogen Ion Implantation, Corrosion, 52 (1996) 921-926.

[84] Y.C. Xin, C.L. Liu, W.J. Zhang, J. Jiang, T.Y. Guoyi, X.B. Tian, P.K. Chua, Electrochemical behavior Al2O3/Al coated surgical AZ91 magnesium alloy in simulated body fluids, Journal of The Electrochemical Society, 155 (2008) C178-C182.

[85] A.M. Fekry, M.A. Ameer, Electrochemistry and impedance studies on titanium and magnesium alloys in Ringer's solution, International Journal of Electrochemical Science, 6 (2011) 1342-1354.

[86] B. Hirschorn, M.E. Orazem, B. Tribollet, V. Vivier, I. Frateur, M. Musiani, Determination of effective capacitance and film thickness from constant-phase-element parameters, Electrochimica Acta, 55 (2010) 6218-6227.

[87] M.M. Avedesian, H. Baker, Magnesium and Magnesium Alloys, ASM International, (1999).

[88] Y. Wang, Z. Fan, X. Zhou, G. Thompson, Characterisation of magnesium oxide and its interface with $\alpha-\mathrm{Mg}$ in $\mathrm{Mg}-\mathrm{Al}-\mathrm{based}$ alloys, Philosophical Magazine Letters, 91 (2011) 516-529.

[89] J.P. Pemsler, Diffusion of Oxygen in Zirconium and Its Relation to Oxidation and Corrosion, Journal of The

Electrochemical Society, 105 (1958) 315-322.

[90] S.H. Salleh, S. Thomas, J.A. Yuwono, K. Venkatesan, N. Birbilis, Enhanced hydrogen evolution on Mg (OH)2 covered Mg surfaces, Electrochimica Acta, 161 (2015) 144-152.

[91] C. Wagner, Theoretical analysis of the diffusion processes determining the oxidation rate of alloys, Journal of The Electrochemical Society, 99 (1952) 369-380.

[92] J.M. Zhang, D.D. Want, K.W. Xu, Calculation of the surface energy of hcp metals by using the modified embedded atom method, Applied Surface Science, 253 (2006) 2018-2024.

[93] F. Cao, Z. Shi, J. Hofstetter, P.J. Uggowitzer, G. Song, M. Liu, A. Atrens, Corrosion of ultra-high-purity $\mathrm{Mg}$ in $3.5 \% \mathrm{NaCl}$ solution saturated with $\mathrm{Mg}(\mathrm{OH})_{2}$, Corrosion Science, 75 (2013) 78-99. 
[94] Z. Shi, F. Cao, G.L. Song, M. Liu, A. Atrens, Corrosion behaviour in salt spray and in $3.5 \% \mathrm{NaCl}$ solution saturated with $\mathrm{Mg}(\mathrm{OH})_{2}$ of as-cast and solution heat-treated binary $\mathrm{Mg}-\mathrm{RE}$ alloys: RE=Ce, La, Nd, Y, Gd, Corrosion Science, 76 (2013) 98 118. 
Table 1. Composition of 99.9\% Mg Rod (Alfa Aesar). All compositions reported in wt. \%, with the actual compositions provided by QUANT (Quality Analysis and Testing Corporation).

\begin{tabular}{|c|c|c|c|c|c|c|c|c|}
\hline & $\mathrm{Al}$ & $\mathrm{Mn}$ & $\mathrm{Zn}$ & $\mathrm{Si}$ & $\mathrm{Cu}$ & $\mathrm{Ni}$ & $\mathrm{Fe}$ & $\mathrm{Mg}$ \\
\hline $\mathrm{Mg} \operatorname{Rod}$ & 0.01 & 0.01 & 0.01 & 0.021 & 0.005 & 0.001 & 0.006 & Bal. \\
\hline
\end{tabular}


Table 2. Typical fitting results of electrochemical impedance measurements made on commercially pure $\mathrm{Mg}$, in $0.6 \mathrm{M} \mathrm{NaCl}, 0.1 \mathrm{M}$ TRIS and $0.1 \mathrm{M}$ EDTA solution at open circuit after $24 \mathrm{~h}$ of immersion, as per the equivalent circuits seen in Figure 2.

\begin{tabular}{|c|c|c|c|}
\hline & $0.6 \mathrm{M} \mathrm{NaCl}$ & $0.1 \mathrm{M}$ TRIS & $0.1 \mathrm{M}$ EDTA \\
\hline $\mathrm{R}_{\mathrm{s}}\left(\Omega \cdot \mathrm{cm}^{2}\right)$ & 23 & 37 & 40 \\
\hline $\mathrm{C}_{1}\left(\mu \mathrm{F} \mathrm{cm} \mathrm{cm}^{-2}\right)$ & $2.0 \times 10^{-6}$ & $1.5 \times 10^{-5}$ & $1.0 \times 10^{-5}$ \\
\hline $\mathrm{R}_{1}\left(\Omega \cdot \mathrm{cm}^{2}\right)$ & 720 & 140 & 190 \\
\hline $\mathrm{C}_{2}\left(\mu \mathrm{F} \cdot \mathrm{cm}^{-2}\right)$ & $2.0 \times 10^{-5}$ & $2.0 \times 10^{-3}$ & $8.0 \times 10^{-3}$ \\
\hline $\mathrm{R}_{2}\left(\Omega \cdot \mathrm{cm}^{2}\right)$ & 170 & 220 & 130 \\
\hline $\mathrm{L}\left(\Omega \cdot \mathrm{s} \cdot \mathrm{cm}^{2}\right)$ & 400 & -- & 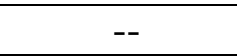 \\
\hline $\mathrm{R}_{3}\left(\Omega \cdot \mathrm{cm}^{2}\right)$ & 920 & -- & -- \\
\hline
\end{tabular}

$\begin{array}{ll}\text { Bland } & 28\end{array}$ 
Table 3. Relative Raman peak intensity ratios of $\mathrm{MgOH}_{2}$ as determined via Raman Spectroscopy in 0.6 M NACl, 0.1 M TRIS and 0.1 M EDTA.

\begin{tabular}{|c|c|c|}
\hline & $442 \mathrm{~cm}^{-1}$ & $278 \mathrm{~cm}^{-1}$ \\
\hline$\left[\mathrm{MgOH}_{2}\right.$ in $\left.\mathrm{NaCl}\right] /\left[\mathrm{MgOH}_{2}\right.$ in $\left.\mathrm{NaCl}\right]$ & 1 & 1 \\
\hline$\left[\mathrm{MgOH}_{2}\right.$ in TRIS $] /\left[\mathrm{MgOH}_{2}\right.$ in $\left.\mathrm{NaCl}\right]$ & 0.3 & 0.5 \\
\hline$\left[\mathrm{MgOH}_{2}\right.$ in EDTA $] /\left[\mathrm{MgOH}_{2}\right.$ in $\left.\mathrm{NaCl}\right]$ & 0.1 & 0.4 \\
\hline
\end{tabular}


a)

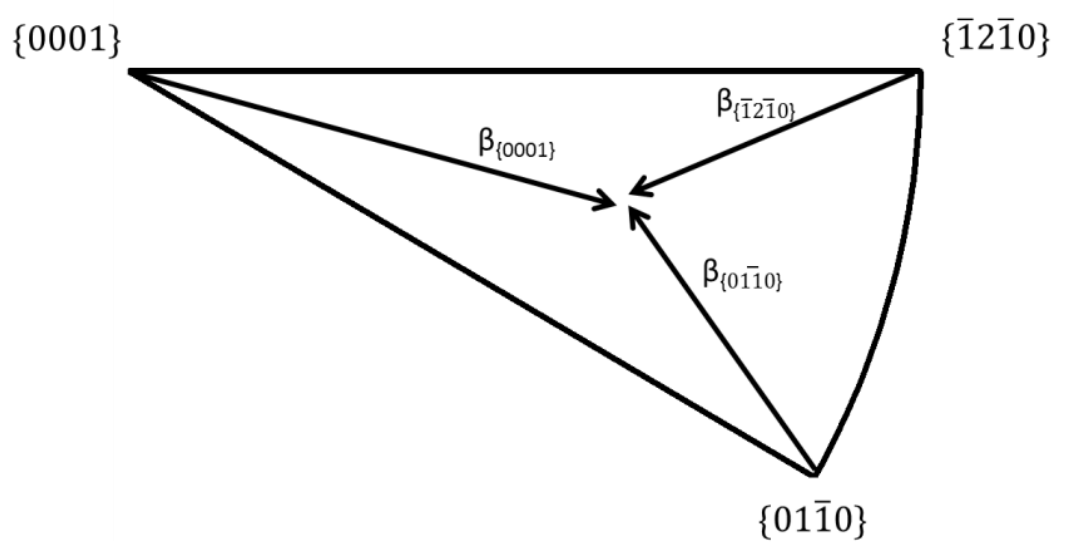

b)

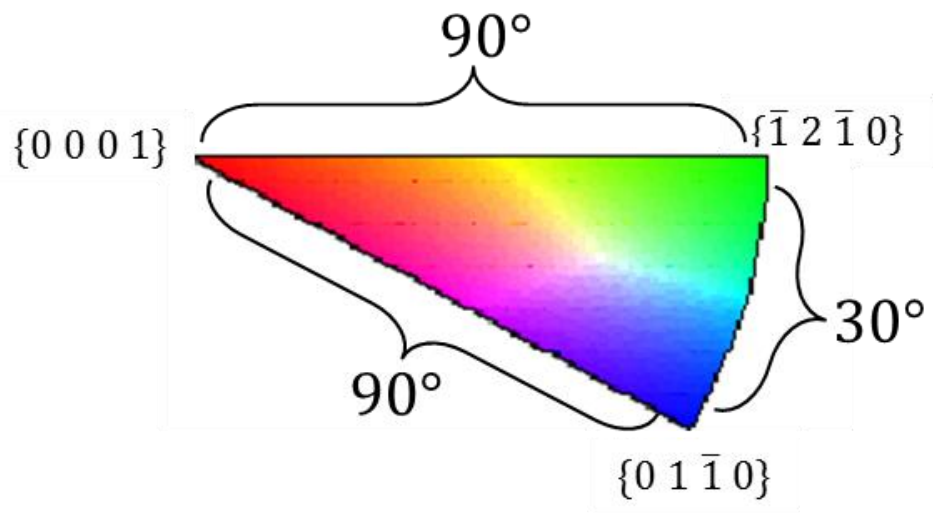

Figure 1. Schematic representation of $\{$ hkil $\}$ positions defined by the angular distance, $\beta_{\mathrm{i}}$, from the 3 common low index hexagonal planes: $\{0001\},\{01 \overline{1} 0\}$ and $\{\overline{1} 2 \overline{1} 0\}$. 
a)

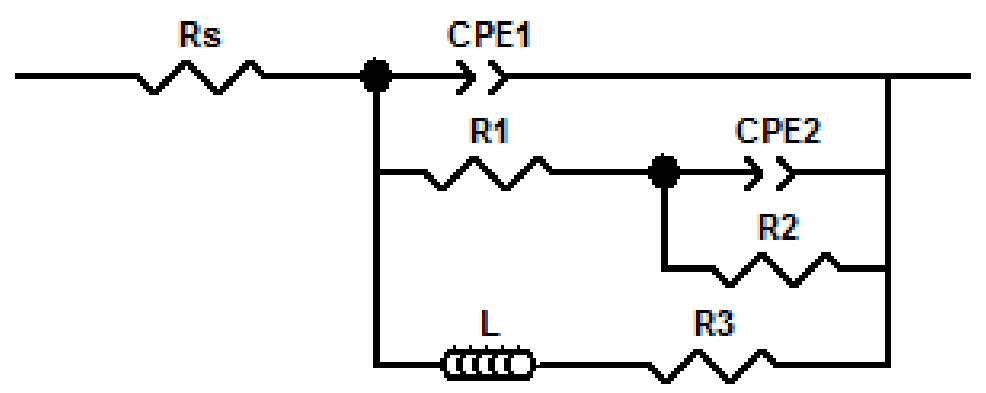

b)

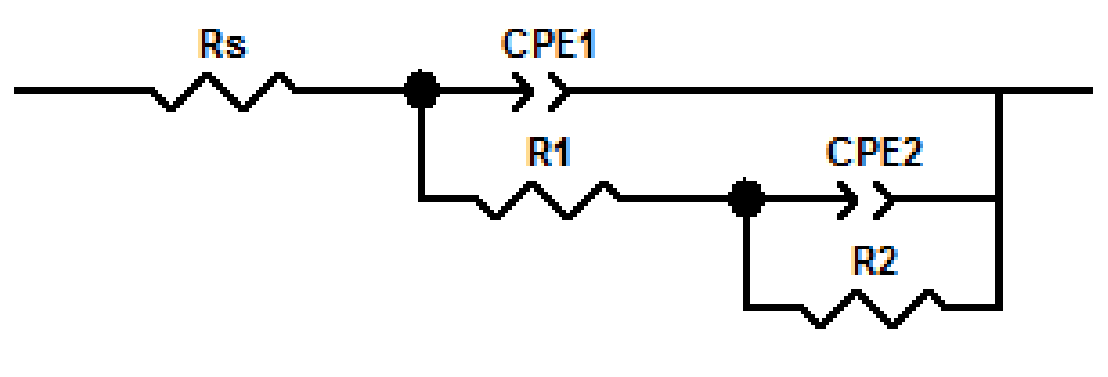

Figure 2. (a) Electrical equivalent circuit diagram used to model pseudo-inductive electrochemical impedance response and to determine $\mathrm{R}_{\mathrm{p}}$ on corroding $\mathrm{Mg}$ in $0.6 \mathrm{M} \mathrm{NaCl}$ solution and (b) the equivalent circuit diagram used to determine the oxide thickness and $\mathrm{R}_{\mathrm{p}}$ in $0.1 \mathrm{M}$ TRIS and EDTA. Constant phase elements were modeled using ideal capacitors when $\alpha$ was within $10 \%$ of 1 . 
a)

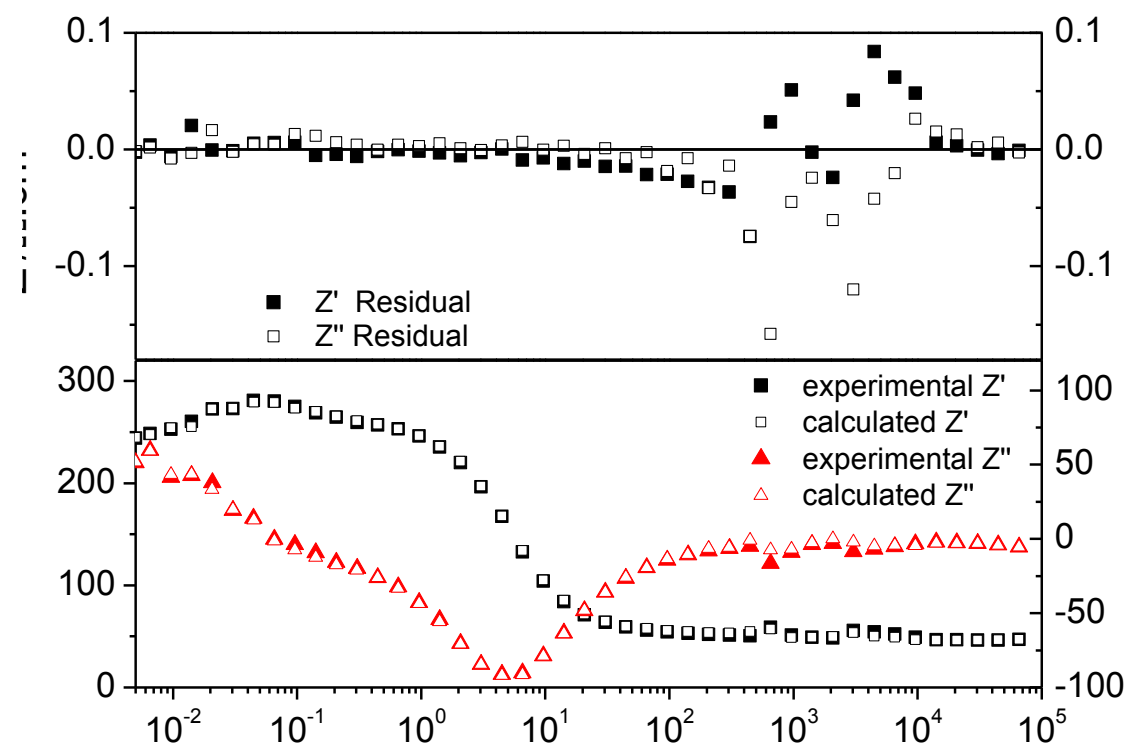

b)

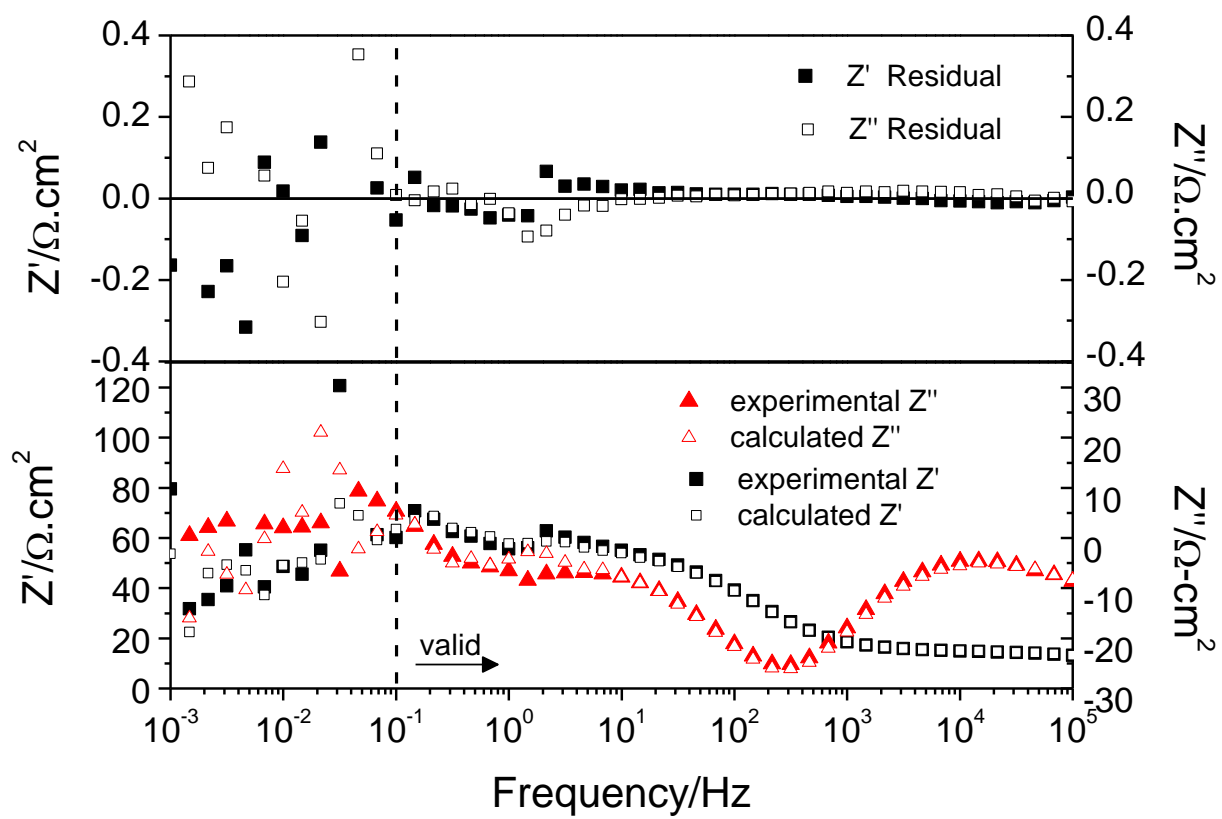

Bland 
c)

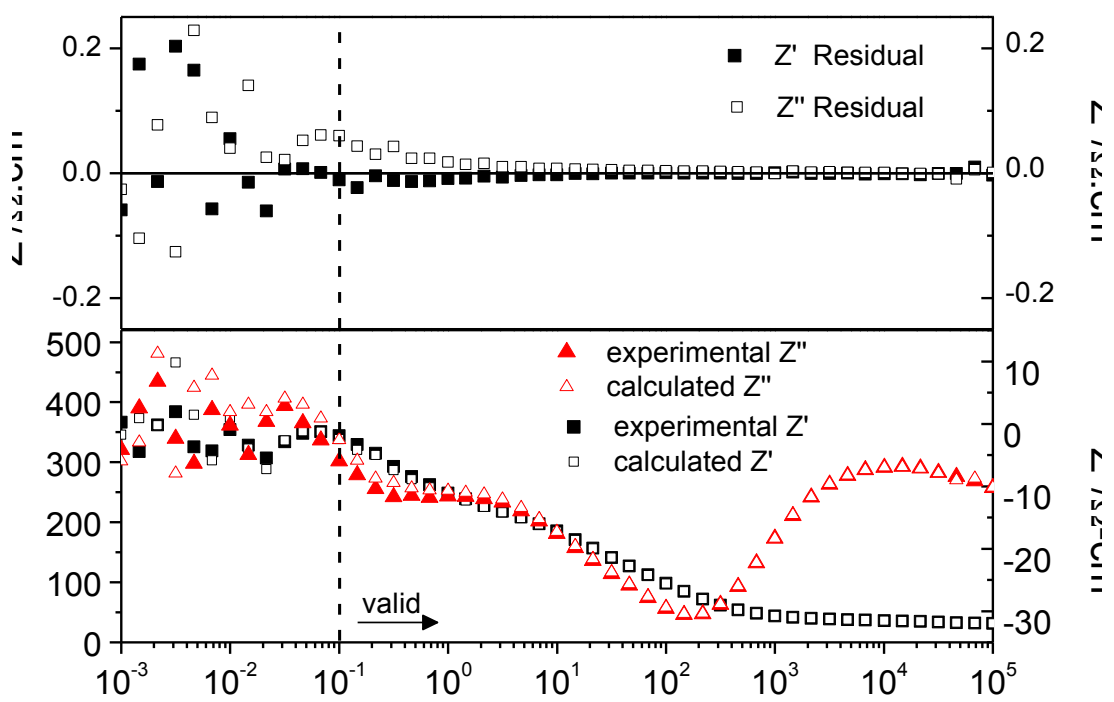

Figure 3. Typical Kramers-Kronig transforms of the real and imaginary components of the impedance of high purity $\mathrm{Mg}$ after $24 \mathrm{~h}$ immersion in (a) $0.6 \mathrm{M} \mathrm{NaCl}$, (b) $0.1 \mathrm{M}$ EDTA and (c) $0.1 \mathrm{M}$ TRIS. 

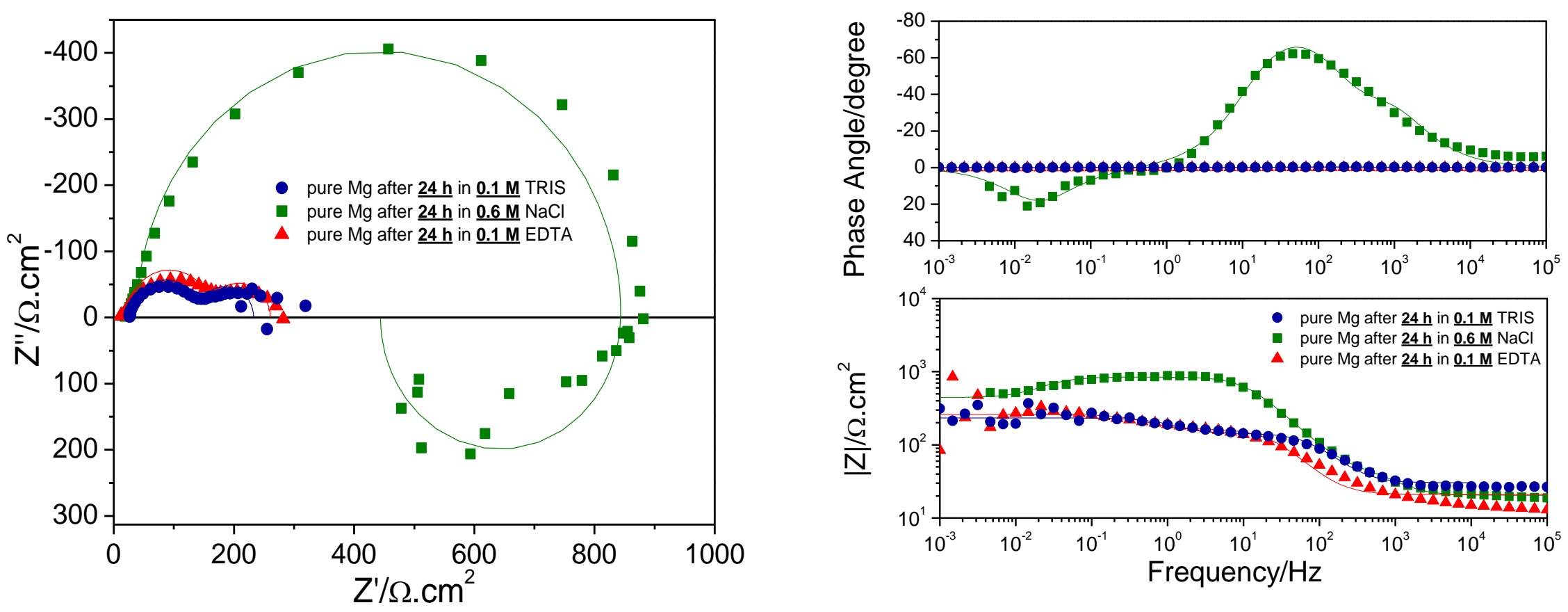

Figure 4. (left) Nyquist plots and (right) Bode magnitude and phase plot for pure polycrystalline Mg. Data shown along with respective fits following $24 \mathrm{~h}$ immersion in $0.6 \mathrm{M} \mathrm{NaCl}, 0.1 \mathrm{M}$ TRIS and $0.1 \mathrm{M}$ EDTA at open circuit. Parameters reported in Table 2. 
a)

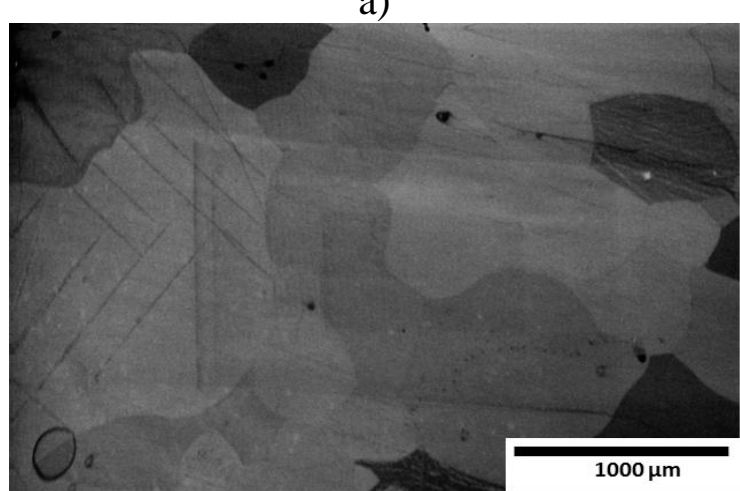

d)

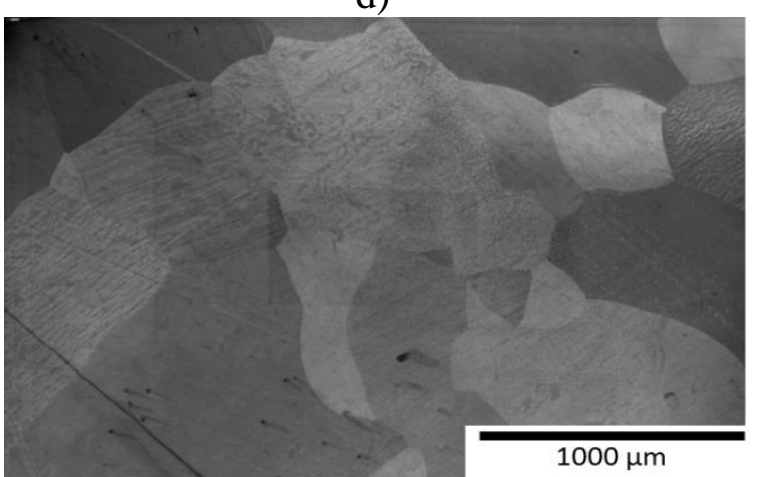

b)

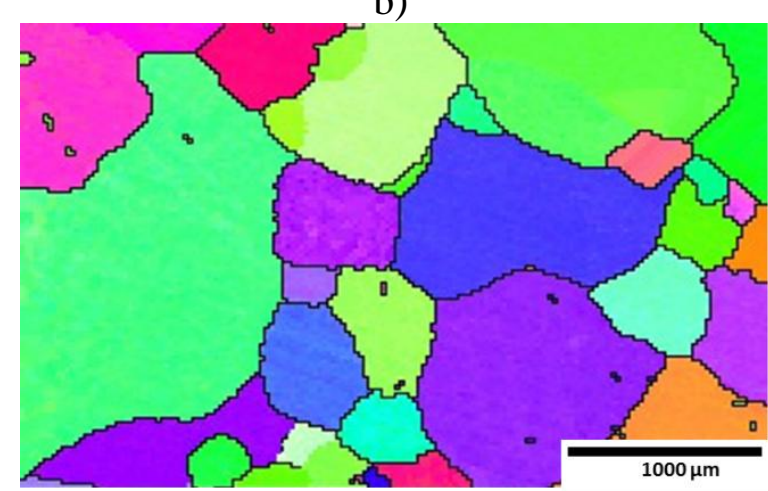

e)

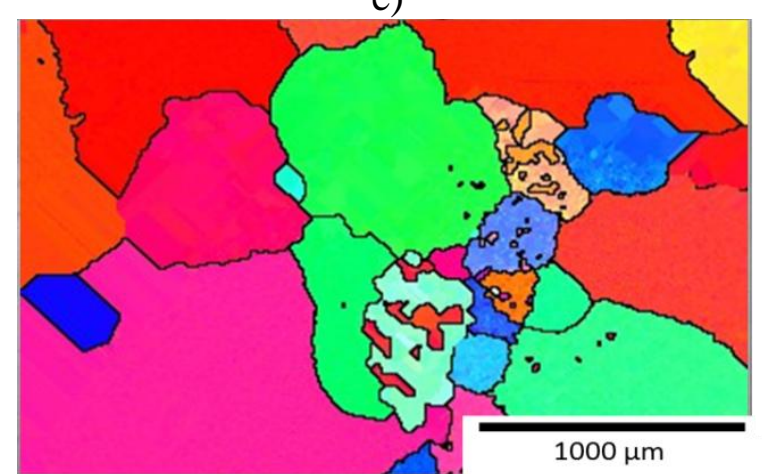

c)

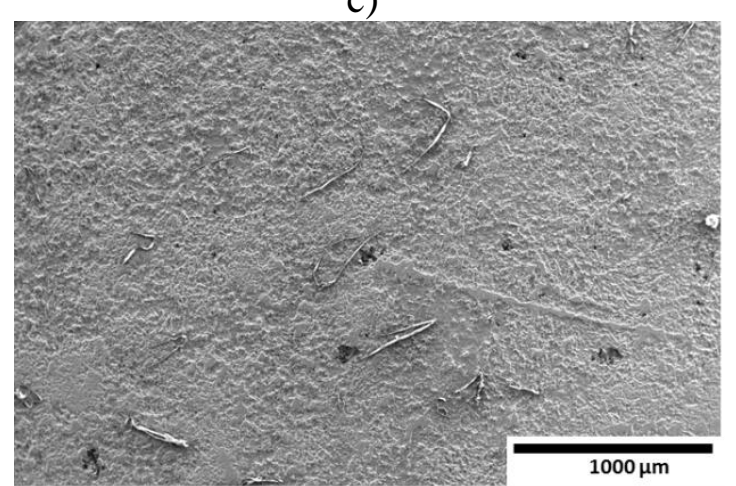

f)

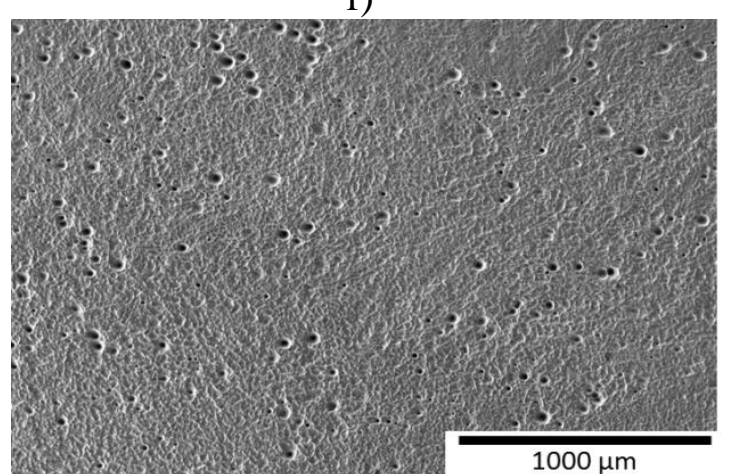

Figure 5. Secondary electron micrographs of (a) commercially pure Mg before exposure, (b) commercially pure Mg EBSD before exposure, (c) commercially pure $\mathrm{Mg}$ after exposure in $0.1 \mathrm{M}$ TRIS, (d) pure Mg before exposure, (e) commercially pure Mg EBSD before exposure, (f) commercially pure $\mathrm{Mg}$ after exposure in 0.1 M EDTA. 

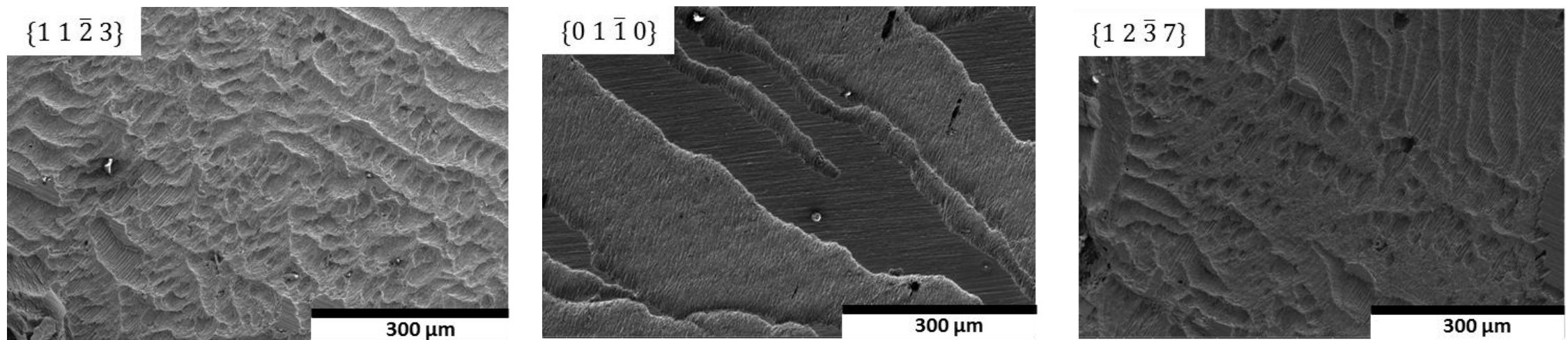

Figure 6. Various grain facets with the indicated crystallographic orientations showing various corrosion morphologies after 12 hours of immersion in $0.6 \mathrm{M} \mathrm{NaCl}$. Samples were cleaned of oxides with $\mathrm{CrO}_{3}$ before imaging. 


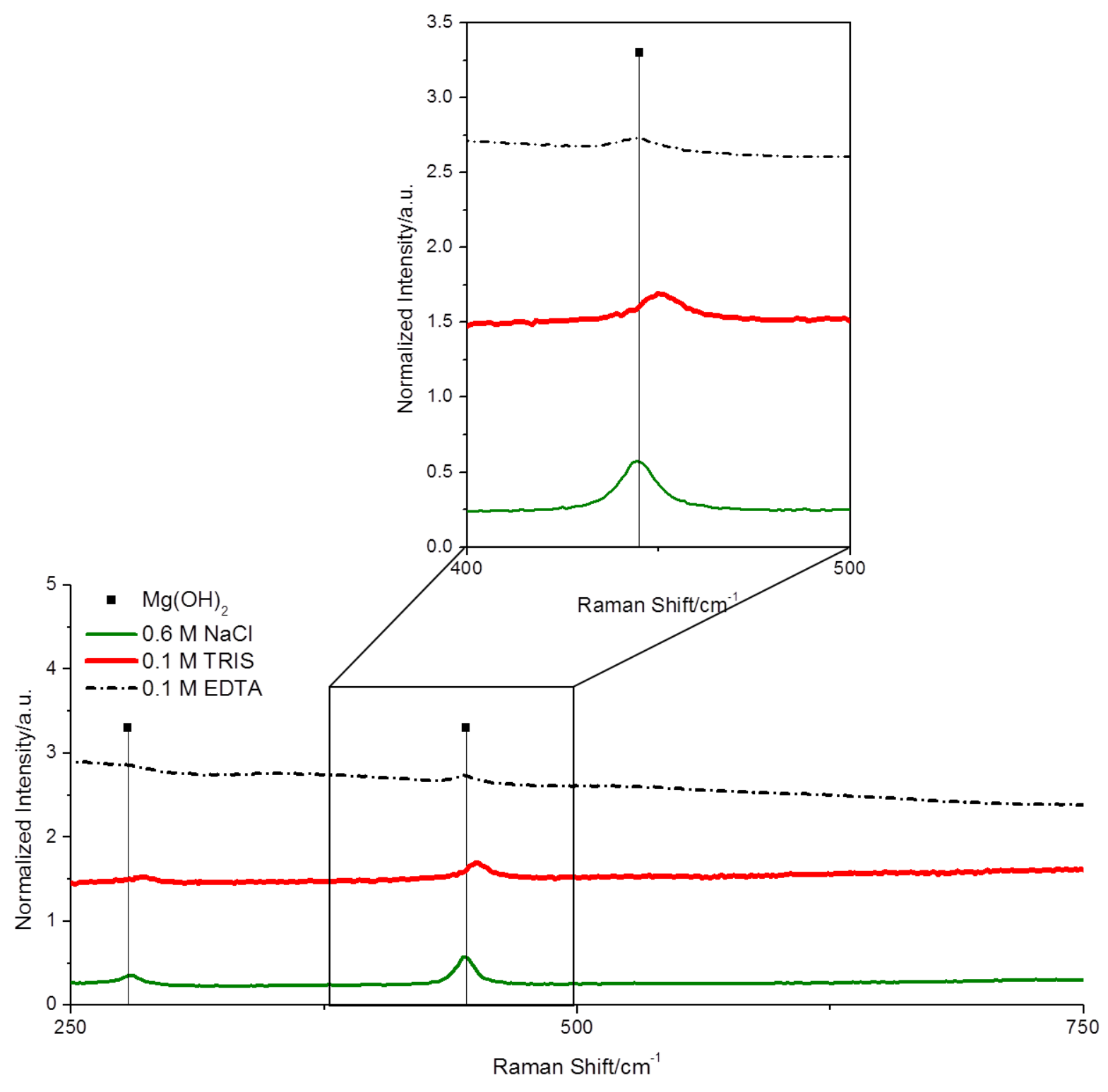

Figure 7. Raman spectrum of oxide growth on commercially pure $\mathrm{Mg}$ after $24 \mathrm{~h}$ at OCP in $0.6 \mathrm{M}$ $\mathrm{NaCl}, 0.1 \mathrm{M}$ TRIS and 0.1 M EDTA. Characteristic Raman spectrum lines for $\mathrm{Mg}(\mathrm{OH})_{2}$ oxide formation are shown according to Raman Standard RRUFF ID: R040077. 
a)

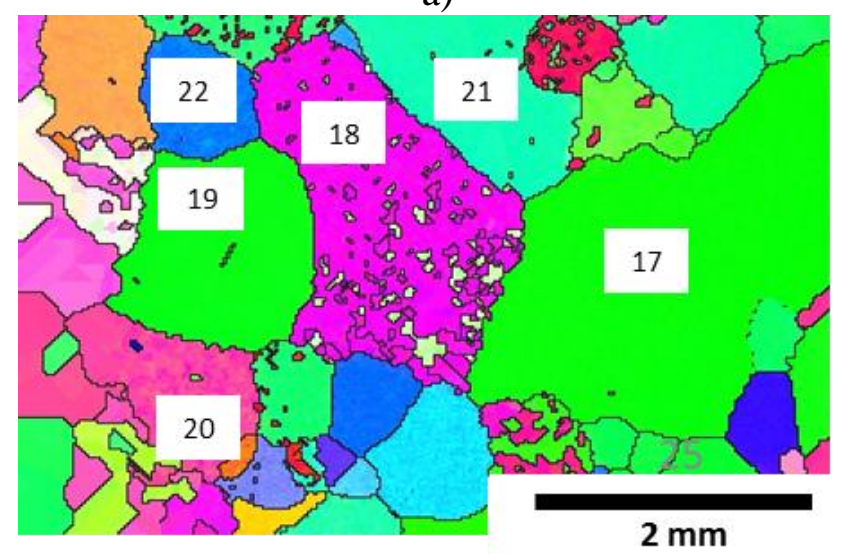

b)

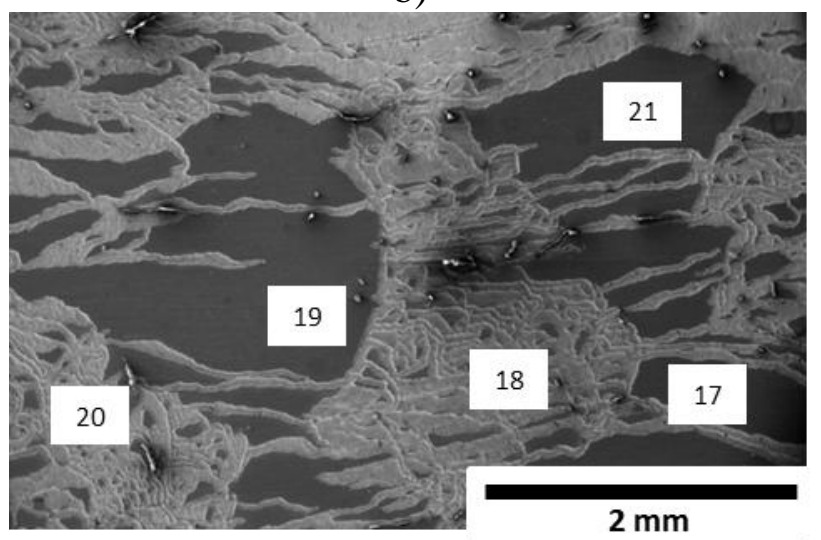

Figure 8. (a) EBSD map of polycrystalline commercially pure Mg and (b) corresponding secondary SEM micrograph showing the marked, specified grains after exposure after $3 \mathrm{~h}$ immersion at $\mathrm{OCP}$ in $0.6 \mathrm{M} \mathrm{NaCl}$ and cleaned with $\mathrm{CrO}_{3}$ to remove any oxides. The color refers to the IPF in Figure 1.

a)

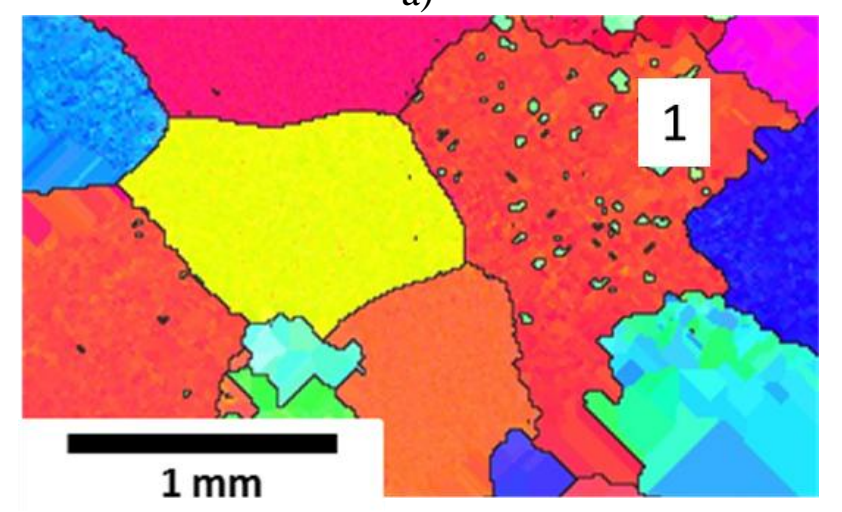

b)

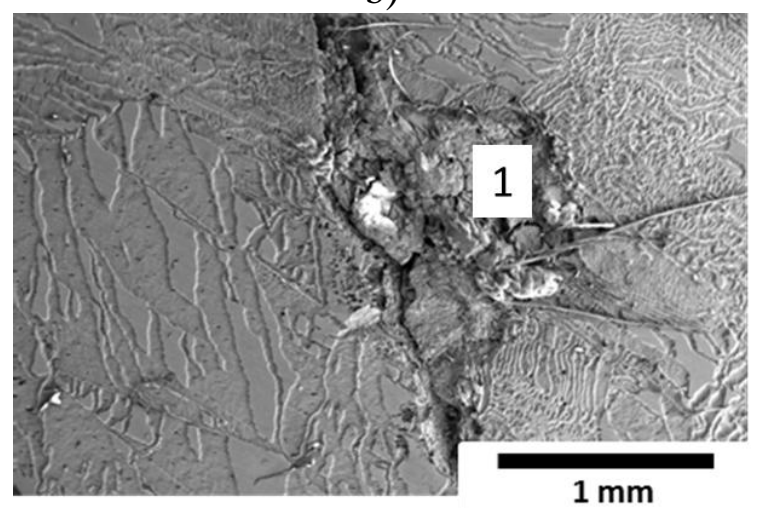

Figure 9.( a) EBSD map showing strongly oriented basal grain and (b) secondary SEM micrograph showing preferential dissolution of the basal oriented grain after exposure after $3 \mathrm{~h}$ immersion at $\mathrm{OCP}$ in $0.6 \mathrm{M} \mathrm{NaCl}$ and cleaned with $\mathrm{CrO}_{3}$ to remove any oxides. The color refers to the IPF in Figure 1. 
a)

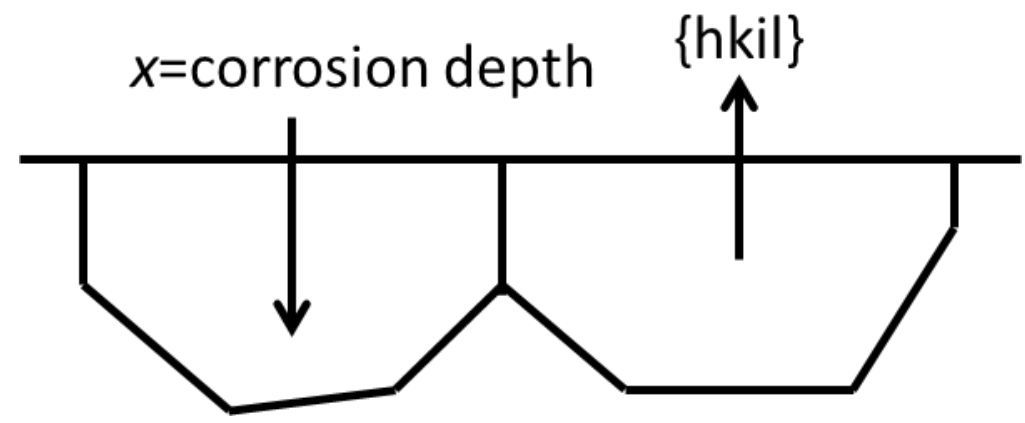

b)

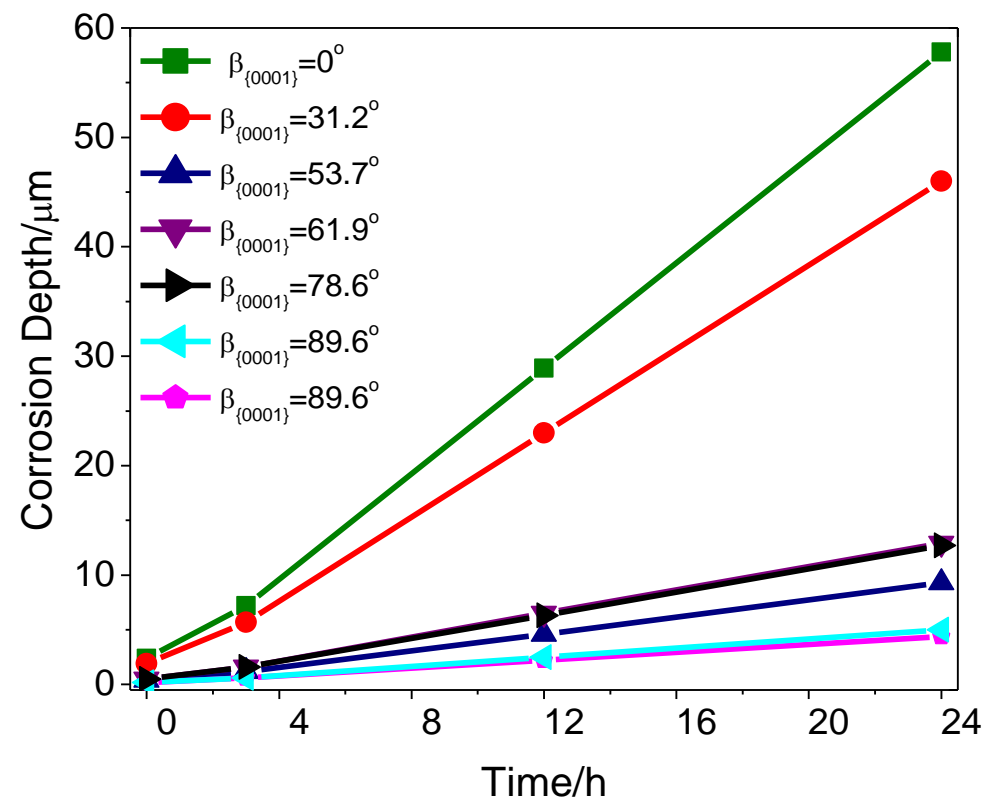

Bland 
c)

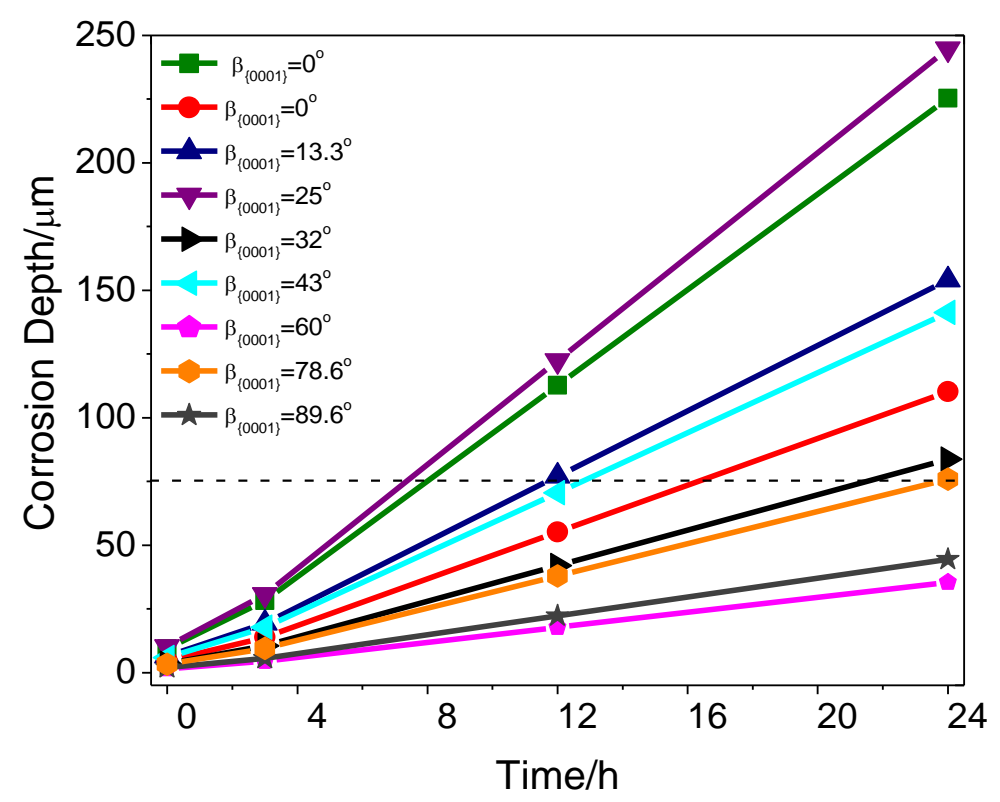

d)

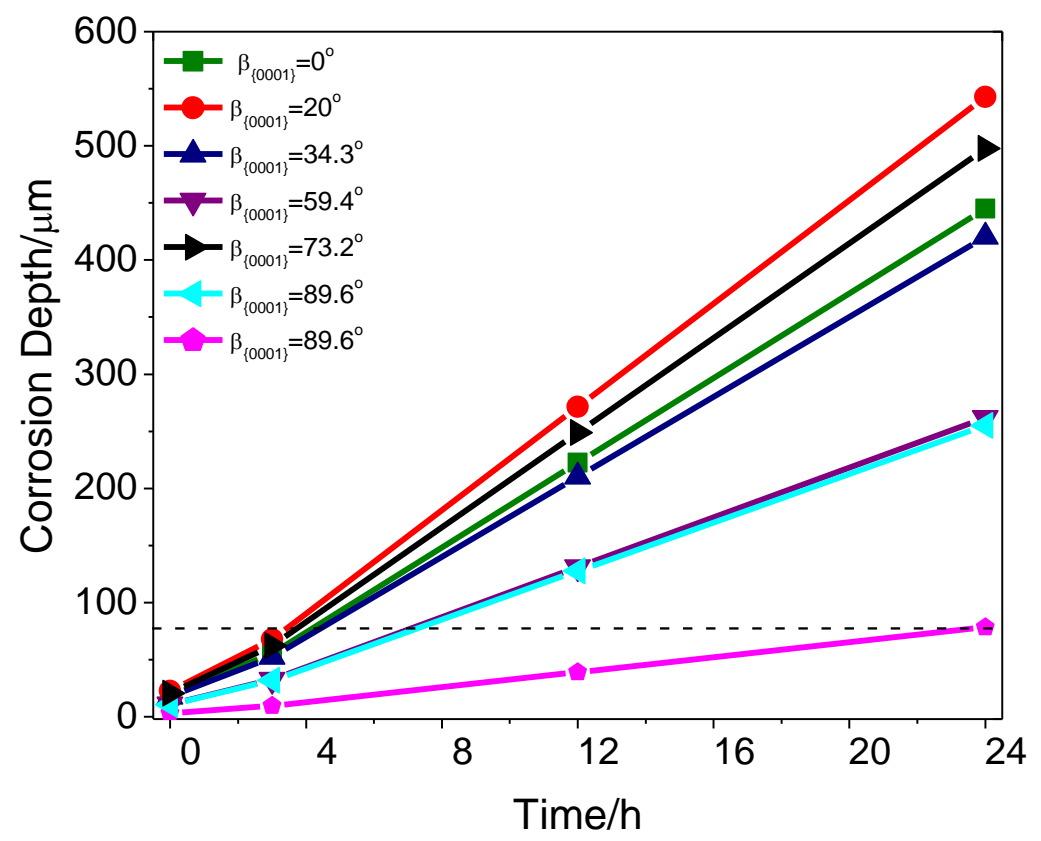

Figure 10. (a) Schematic of corrosion penetration depth assuming uniform corrosion for isolated grains as calculated from EIS determined $\mathrm{j}_{\text {corr }}$ as a function of the $\beta_{\{0001\}}$ angle in (b) $0.6 \mathrm{M} \mathrm{NaCl}$, (c) $0.1 \mathrm{M}$ TRIS and (d) $0.1 \mathrm{M}$ EDTA at OCP over a $24 \mathrm{~h}$ immersion. The dashed line indicates the half grain diameter. 
a)

Relative Activated Dissolution Area \%

- 87.5 to 100

75 to 87.5

62.5 to 75

- 50 to 62.5

- 32.5 to 50

- 25 to 32.5

- 12.5 to 25

- 0 to 12.5

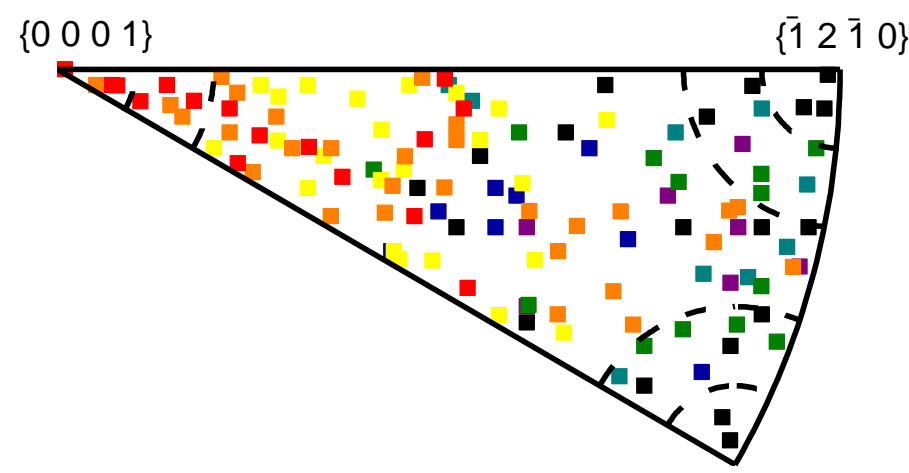

$\left\{\begin{array}{lll}0 & 1 \overline{1} & 0\end{array}\right\}$ b)

Relative Dissolution Volume

- 0.4 to $0.5 \mathrm{~mm}^{3}$

0.3 to $0.4 \mathrm{~mm}^{3}$

- 0.2 to $0.3 \mathrm{~mm}^{3}$

- 0.1 to $0.2 \mathrm{~mm}^{3}$

- 0 to $0.1 \mathrm{~mm}^{3}$

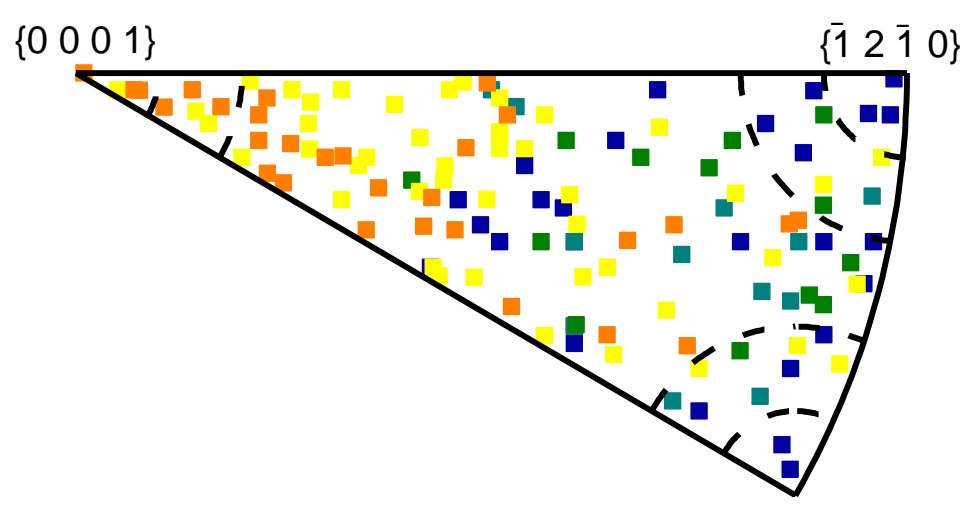

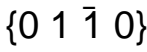

Figure 11. (a) Percent of anodically induced cathodically activated black dissolution area within individual corroded grains with the indicated orientations after $24 \mathrm{~h}$ at OCP for individual grains in $0.6 \mathrm{M} \mathrm{NaCl}$ as determined through ImageJ ${ }^{\mathrm{TM}}$. (b) Relative dissolution volume after $24 \mathrm{~h}$ at $\mathrm{OCP}$ for individual grains in $0.6 \mathrm{M} \mathrm{NaCl}$ as determined through Hirox optical microscopy after cleaning with $\mathrm{CrO}_{3}$. 

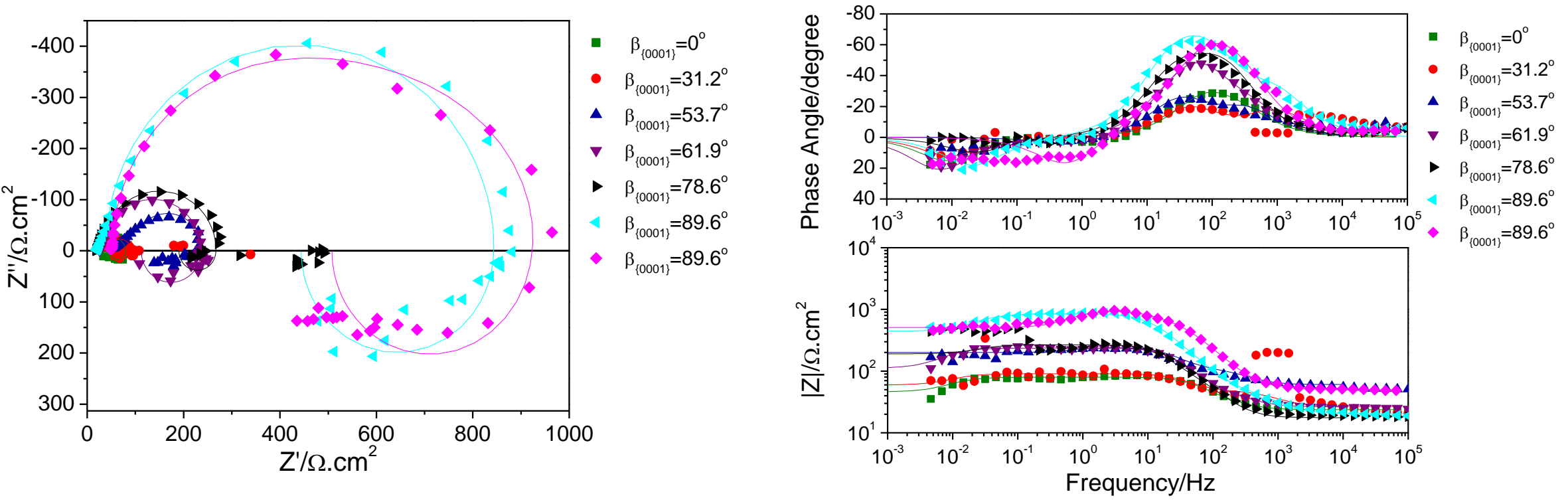

Figure 12. (left) Nyquist plots and (right) Bode magnitude and phase plot for isolated grains with different crystallographic orientations (Beta angle). Data shown along with respective fits following $24 \mathrm{~h}$ immersion in $0.6 \mathrm{M} \mathrm{NaCl}$ at open circuit. 

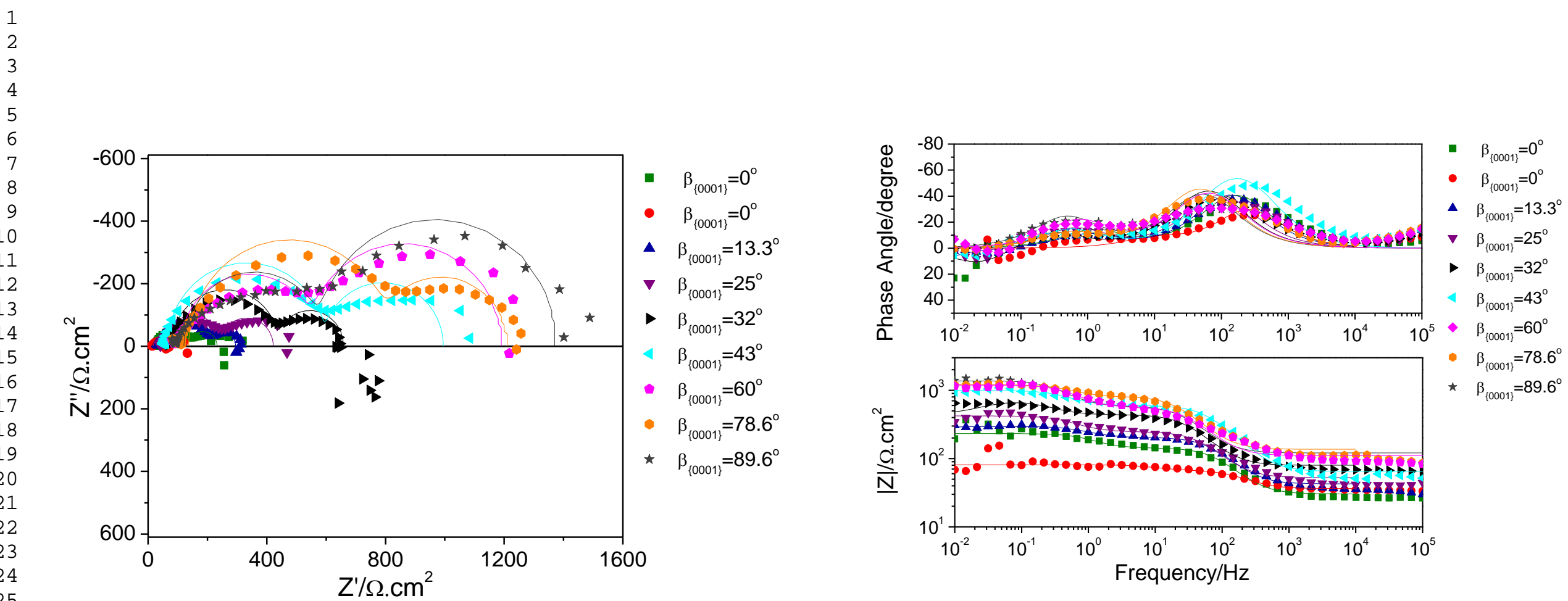

Figure 13. (left) Nyquist plots and (right) Bode magnitude and phase plot for isolated grains with different crystallographic orientations. Data shown along with respective fits following $24 \mathrm{~h}$ immersion in $0.1 \mathrm{M}$ TRIS at open circuit. Invalid data points are removed. 

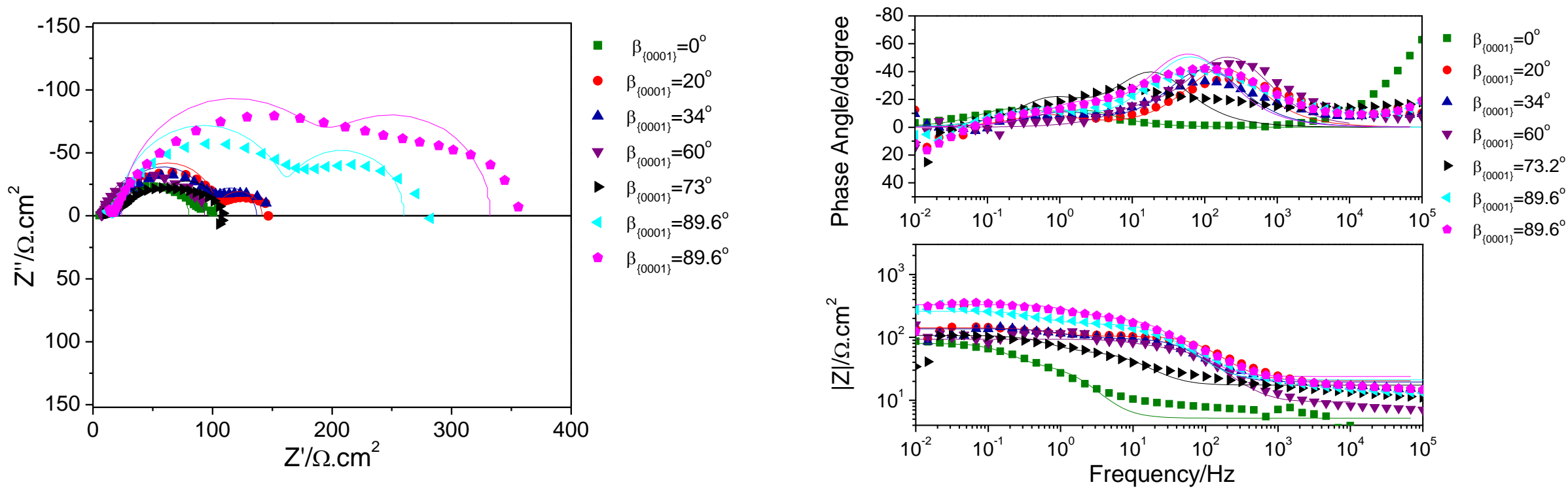

Figure 14. (left) Nyquist plots and (right) Bode magnitude and phase plot for isolated grains with different crystallographic orientations. Data shown along with respective fits following $24 \mathrm{~h}$ immersion in $0.1 \mathrm{M}$ EDTA at open circuit. Invalid data points are removed. 


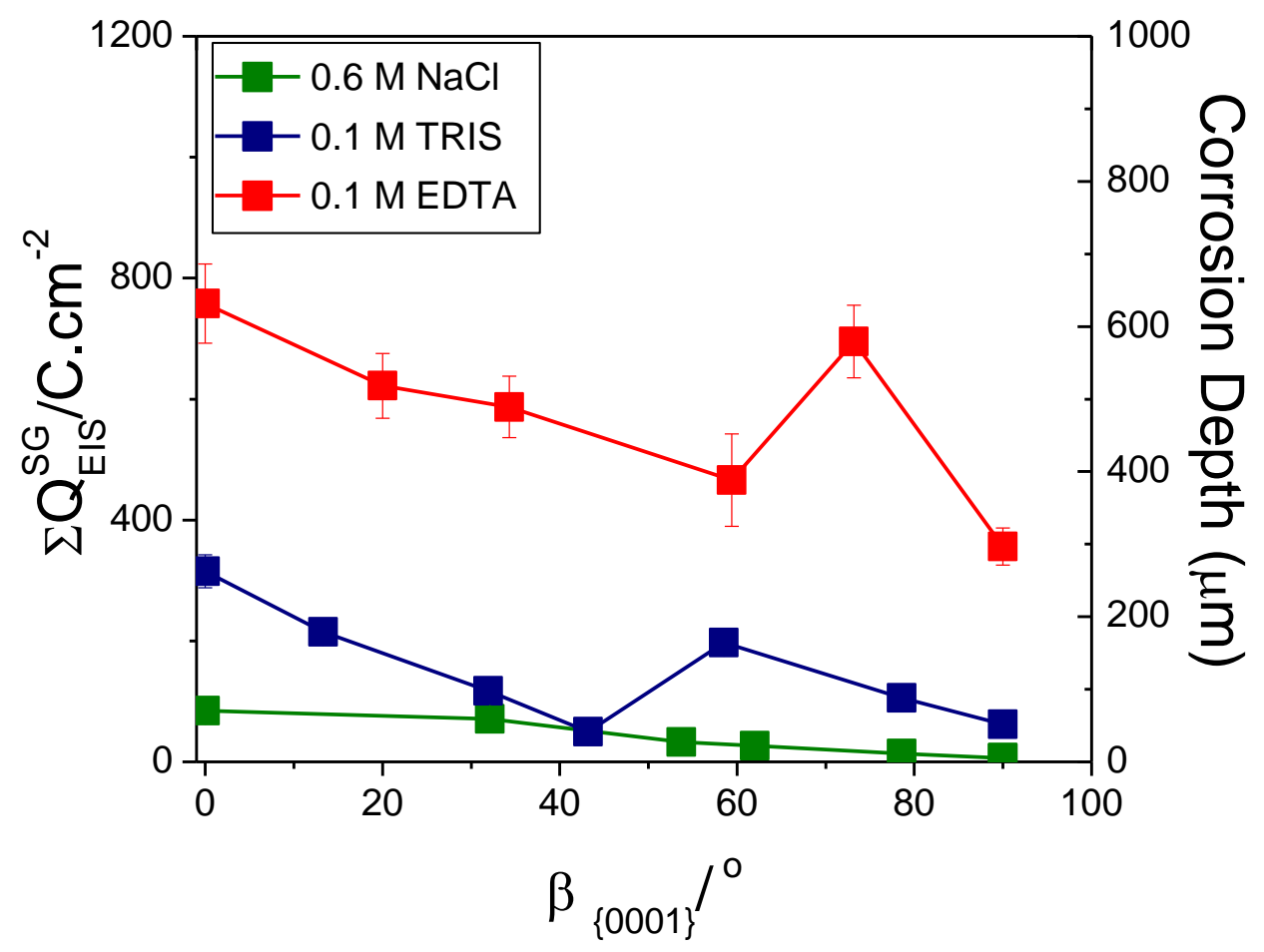

Figure 15. Variation in the electrochemical impedance spectroscopy derived anodic charge density produced as determined at OCP in $0.6 \mathrm{M} \mathrm{NaCl}, 0.1 \mathrm{M}$ TRIS and 0.1 M EDTA over 24 hours as a function of $\beta_{\{0001\}}$. Error bars show the deviation between the EIS determined corrosion rate with various Tafel assumptions [18, 19, 93, 94]. 
a)
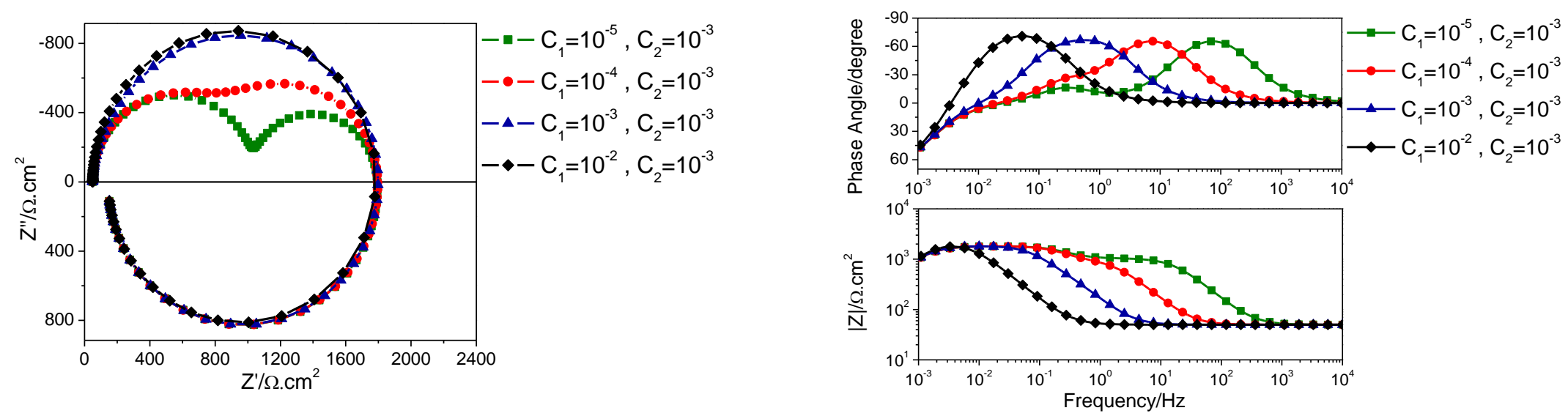

b)
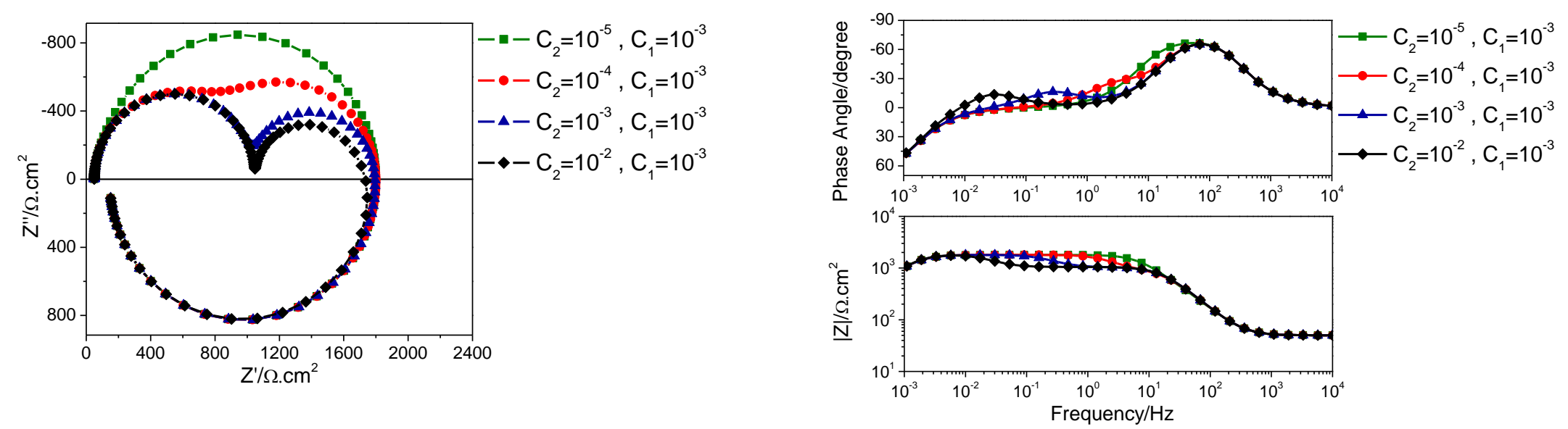

Figure 16. (a) (left) Nyquist plots and (right) Bode magnitude and phase plot with a variation in $\mathrm{C}_{1}$ and $\mathrm{C}_{2}$ kept constant (as labeled in the figure legends). (b) (left) Nyquist plots and (right) Bode magnitude and phase plot with a variation in $\mathrm{C}_{2}$ and $\mathrm{C}_{1}$ kept constant (as labeled in the figure legends). Units for $\mathrm{C}$ are $\mathrm{F} \cdot \mathrm{cm}^{-2} \cdot \mathrm{R}_{1}=\mathrm{R}_{2}=800 \Omega \cdot \mathrm{cm}^{2} \cdot \mathrm{R}_{3}=50 \Omega \cdot \mathrm{cm}^{2} . \mathrm{L}=1 \times 10^{6}(1 \mathrm{Henry}) \mathrm{ohm} \cdot \mathrm{s} \cdot \mathrm{cm}^{2}$.

Bland 
a)
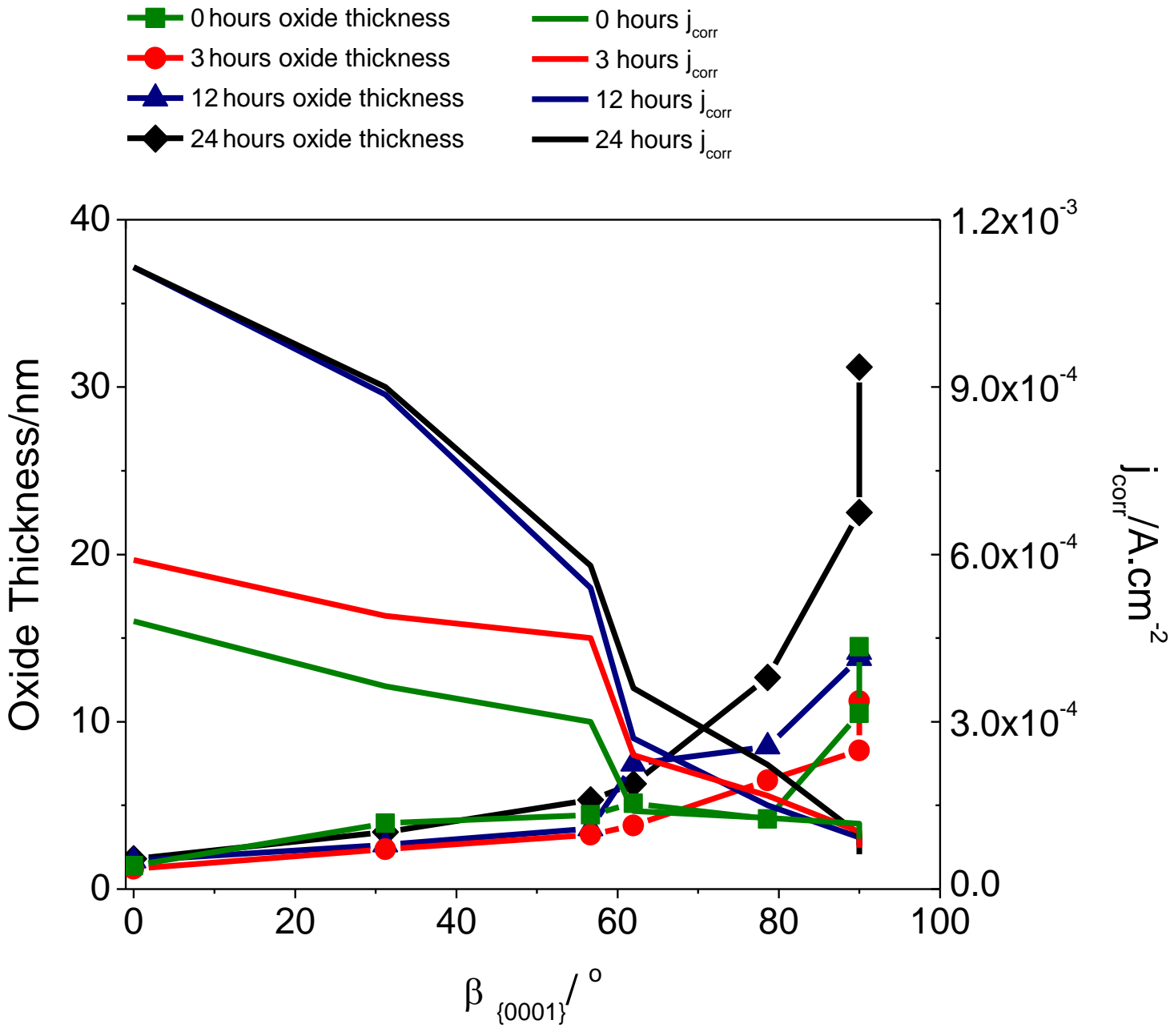

Bland 
b)

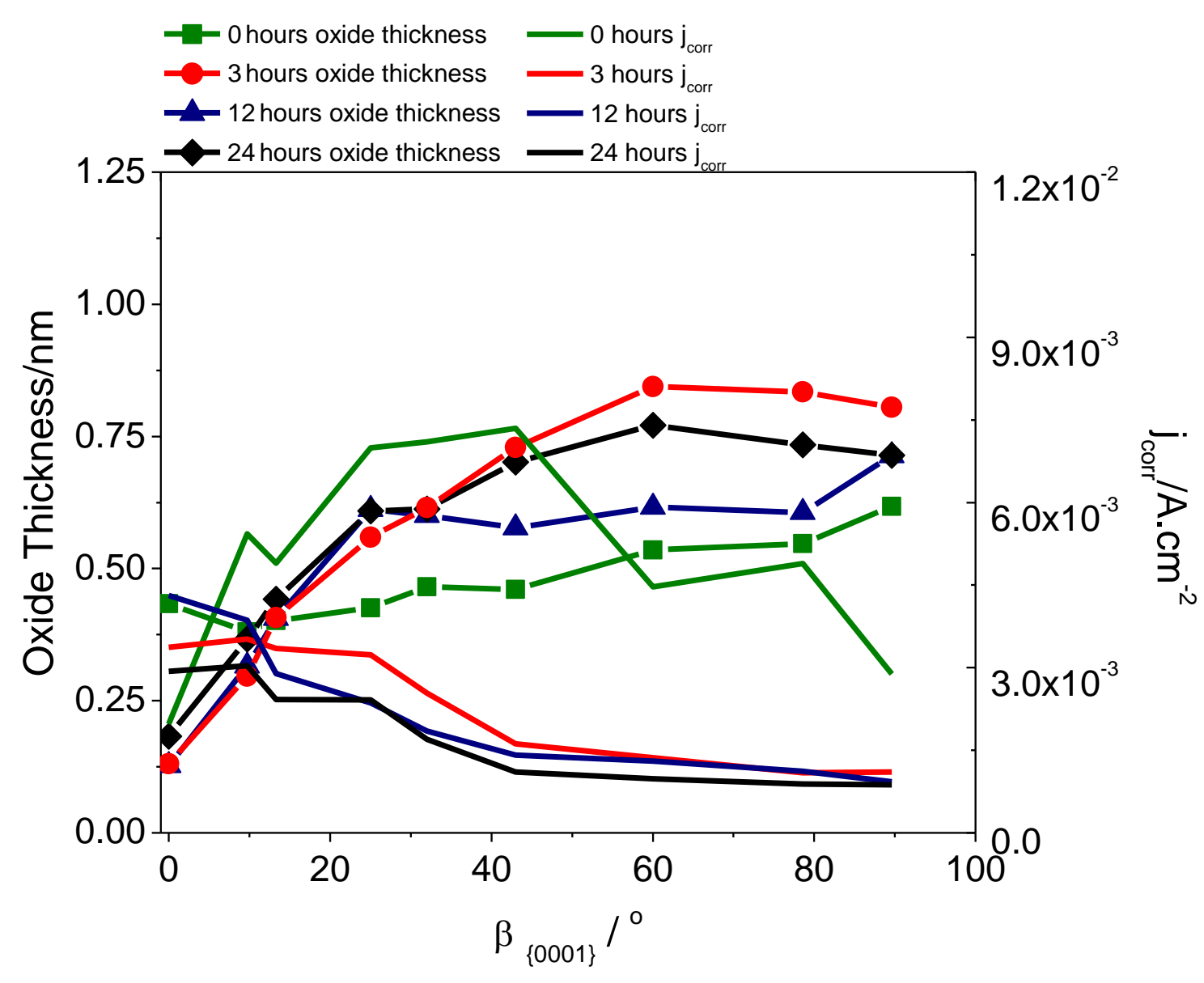

Bland 
Figure 17. Oxide thickness and EIS determined $\mathrm{j}_{\text {corr }}$ as a function of $\beta$ (0001) angle in (a) $0.6 \mathrm{M}$ $\mathrm{NaCl}$, (b) 0.1 M TRIS and (c) 0.1 M EDTA at OCP over a $24 \mathrm{~h}$ immersion as determined through an equivalent circuit shown in Figure 2 composed of CPEs. 


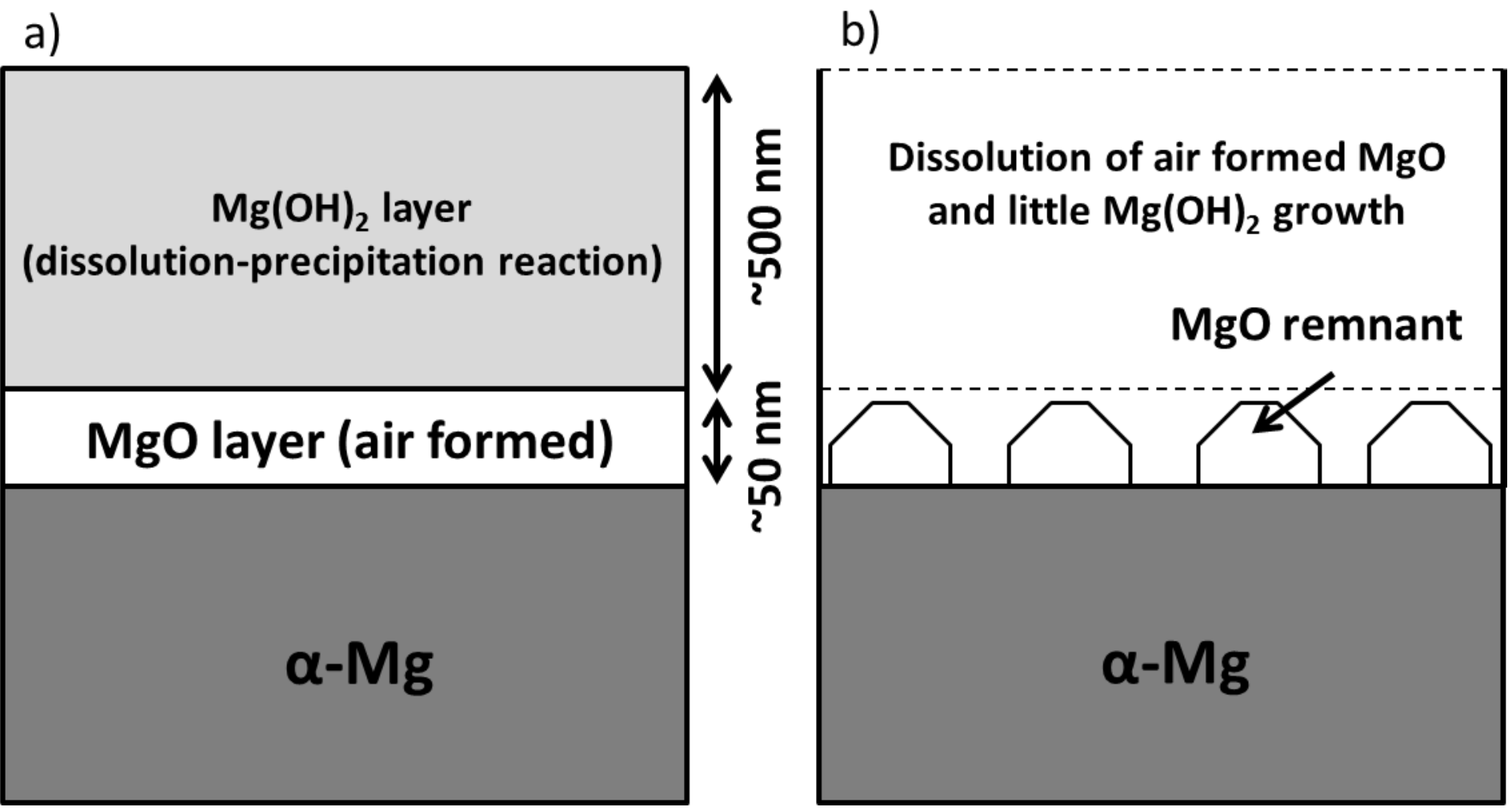

Figure 18. Schematic of oxide growth or remnant on $\mathrm{Mg}$ alloys in (a) $0.6 \mathrm{M} \mathrm{NaCl}$ and (b) $0.1 \mathrm{M}$ TRIS and 0.1 M EDTA. Adapted from [39]. 
a)

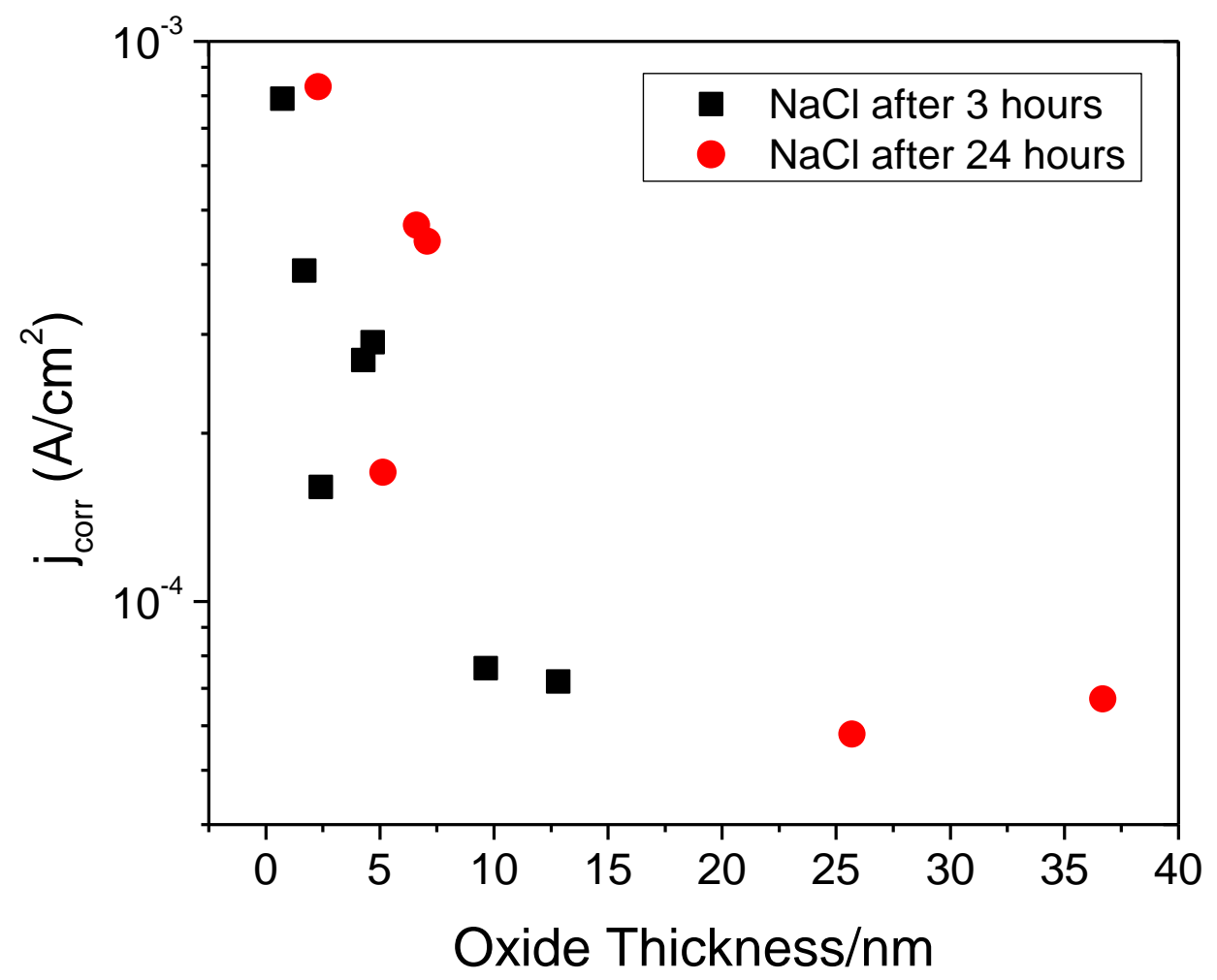

Bland 
b)

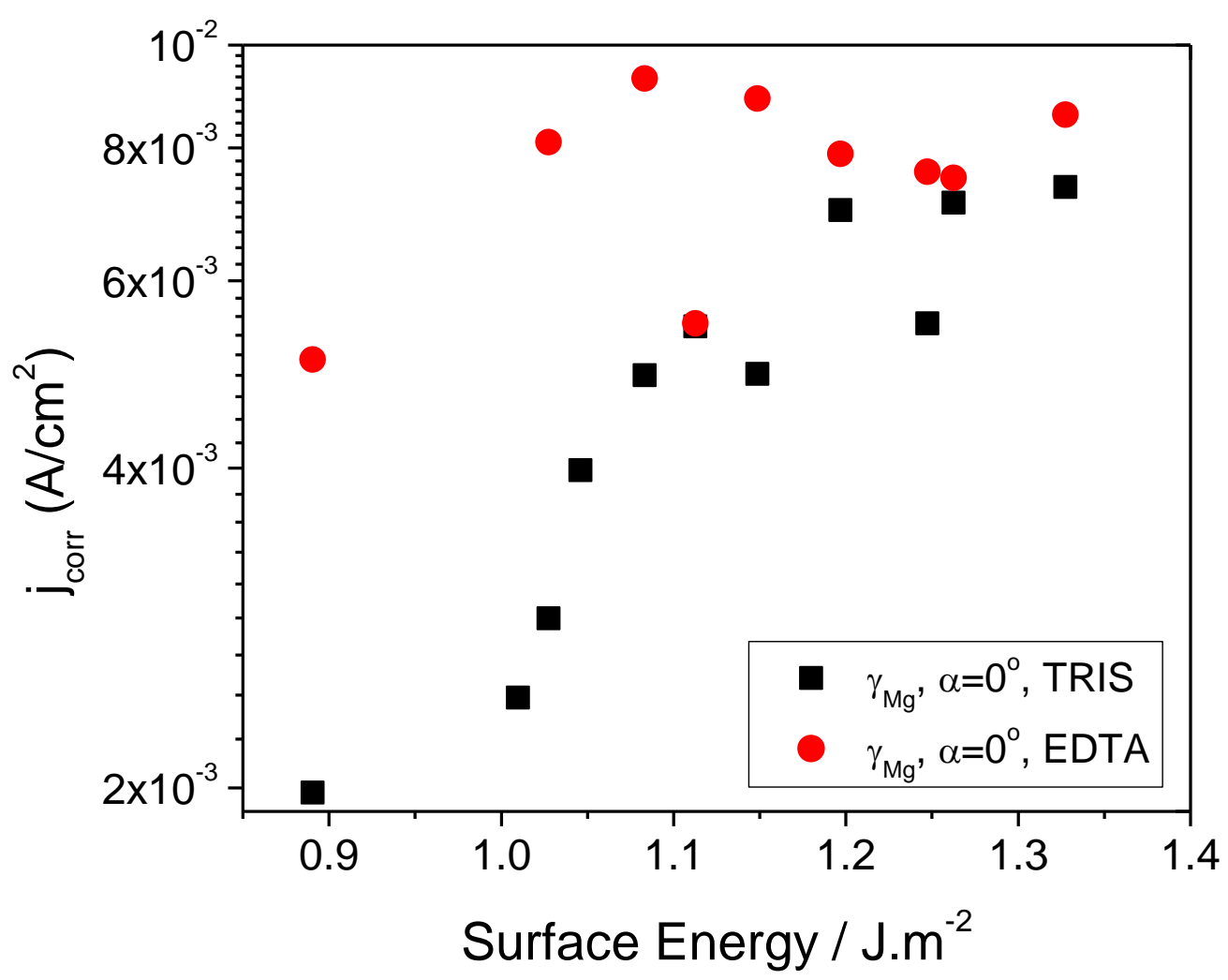

Bland 
c)

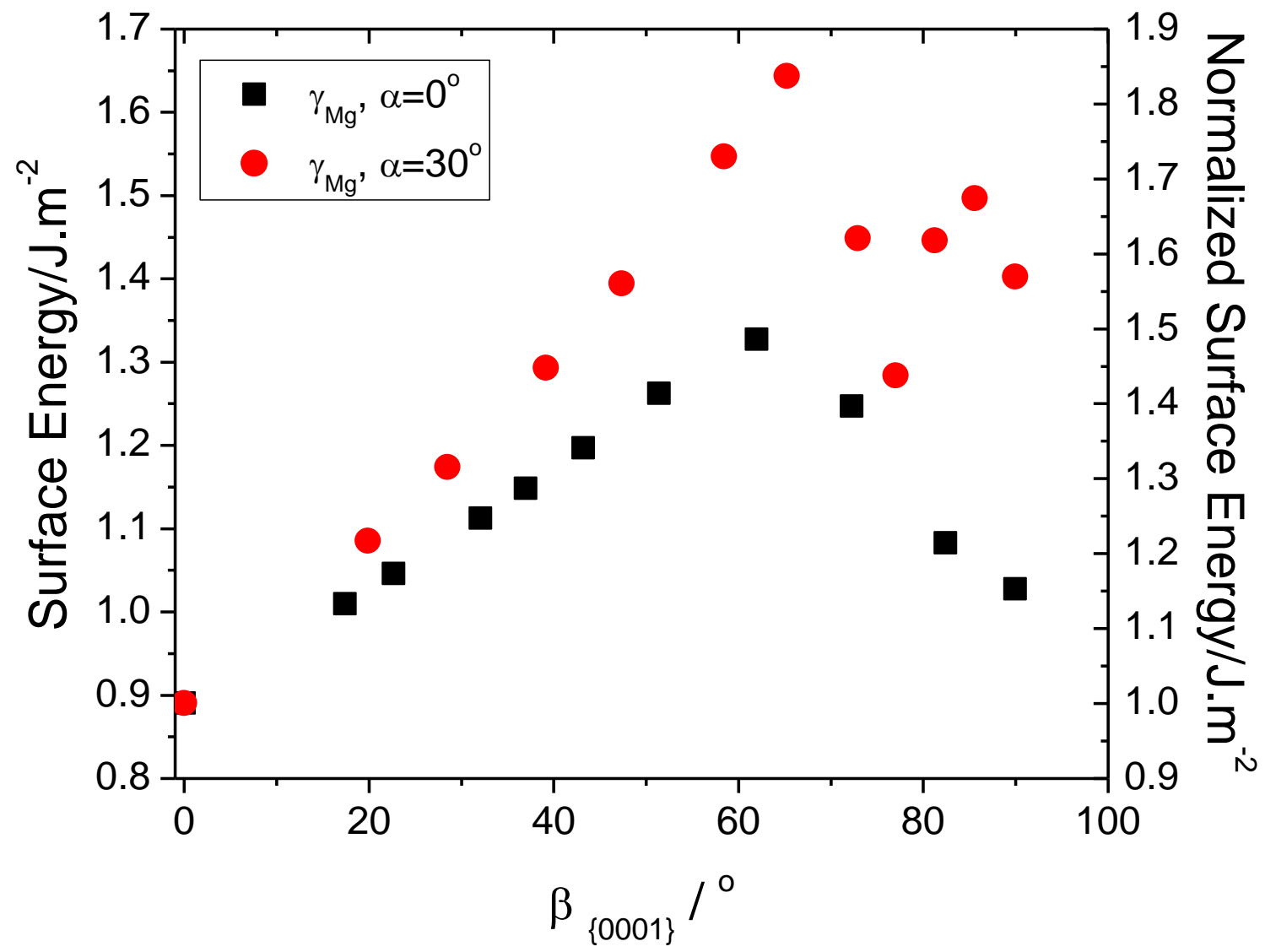

Figure 19. (a) Relationship between $\mathrm{j}_{\text {corr }}$ and oxide thickness for oxide covered surfaces. (b) Relationship between $\mathrm{j}_{\text {corr }}$ with surface energy for bare surfaces (c) Calculated surface energy, $\gamma$, as a function of $\beta_{\{0001\}}$ at $\alpha=0$ and $30^{\circ}$ [92]. The highest surface energy occurs at orientations around $\beta_{\{0001\}}=60-70^{\circ}$. 